\title{
Frequent N Addition and Clonal Relatedness among Immunoglobulin Lambda Light Chains Expressed in Rheumatoid Arthritis Synovia and $P B L$, and the Influence of $V \lambda$ Gene Segment Utilization on CDR3 Length
}

\author{
S. Louis Bridges, Jr. \\ Division of Clinical Immunology and Rheumatology, Department of \\ Medicine and Department of Microbiology, University of Alabama at \\ Birmingham, and the Birmingham Veterans Administration Medical \\ Center, Birmingham, Alabama, U.S.A.
}

Accepted June 23, 1998.

\begin{abstract}
Background: In rheumatoid arthritis (RA), B-lineage cells in the synovial membrane secrete large amounts of immunoglobulin that contribute to tissue destruction. The CDR3 of an immunoglobulin light chain is formed by rearrangements of $V_{L}$ and $J_{L}$ gene segments. Addition of non-germline-encoded $(\mathrm{N})$ nucleotides at $\mathrm{V}(\mathrm{D}) \mathrm{J}$ joins by the enzyme terminal deoxynucleotidyl transferase (TdT) enhances antibody diversity. TdT was previously thought to be active in B cells only during heavy chain rearrangement, but we and others reported unexpectedly high levels of $\mathrm{N}$ addition in kappa light chains. We also found clonally related kappa chains bearing unusually long CDR3 intervals in RA synovium, suggesting oligoclonal expansion of a set of atypical B lymphocytes. In this study, we analyzed lambda light chain expression to determine if $\mathrm{N}$ addition occurs throughout immunoglobulin gene rearrangement and to compare CDR3 lengths of lambda and kappa light chains in RA patients and normal individuals.
\end{abstract}

Materials and Methods: Reverse transcription-polymer-

\section{Introduction}

Rheumatoid arthritis (RA) is a chronic systemic illness characterized by inflammation and hyperplasia of the synovial membrane of affected joints (1-3). Infiltration of the syno-

Address correspondence and reprint requests to: Dr. S. Louis Bridges, Jr., Division of Clinical Immunology and Rheumatology, 415 Lyons-Harrison Research Building, University of Alabama at Birmingham, Birmingham, AL 35294-0007, U.S.A. Phone: (205) 934-7995; Fax: (205) 975-5056; E-mail: lou.bridges@ccc.uab.edu ase chain reaction (RT-PCR) amplification of V VIII transcripts was performed on RA synovia and peripheral blood lymphocytes (PBL) and normal PBL for which kappa repertoires were previously analyzed. Representative $\lambda^{+}$PCR products were cloned and sequenced.

Results: Analysis of $161 \mathrm{cDNA}$ clones revealed that N addition occurs in lambda light chains of RA patients and normal controls. The lambda light chain repertoires in RA were enriched for long CDR3 intervals. In both RA and controls, CDR3 lengths were strongly influenced by which $\mathrm{V} \lambda$ gene segment was present in the rearrangement. Five sets of clonally related sequences were found in RA synovia and PBL; one set was found in normal PBL.

Conclusions: In humans, unlike mice, $\mathrm{N}$ addition enhances antibody diversity at all stages of immunoglobulin assembly, and the structural diversity of lambda CDR3 intervals is greater than that of kappa light chains. Clonally related $V \lambda$ gene segments in RA support an antigen-driven $\mathrm{B}$-cell response. vium by $B$ lymphocytes and plasma cells is a hallmark of the disease and often contributes to joint destruction $(4,5)$. Antibodies are heterodimeric proteins composed of two immunoglobulin heavy $(\mathrm{H})$ chains and two light $(\mathrm{L})$ chains, each of which has a variable (V) domain for antigen recognition. In order to recognize the virtually limitless number of antigens in the environment, multiple mechanisms to generate antibody diversity have evolved. In humans, these include the use of many differ- 
ent gene segments to form antibodies (6), differential pairing of different heavy and light chains, somatic hypermutation, and the insertion of non-germline-encoded $(\mathrm{N})$ nucleotides at the sites of gene segment rearrangement (reviewed in refs. 7-9).

Variable heavy-chain domains are encoded by variable $\left(\mathrm{V}_{\mathrm{H}}\right)$, diversity $\left(\mathrm{D}_{\mathrm{H}}\right)$, and joining $\left(\mathrm{J}_{\mathrm{H}}\right)$ gene segments, which undergo sequential somatic rearrangements to become juxtaposed in the genomic DNA of the B cell (8). After heavy chain rearrangement, the kappa locus undergoes rearrangements of $\mathrm{V}$ and $\mathrm{J}$ gene segments to generate light chain variable domains. If kappa light chain rearrangement fails on both alleles, lambda light chain V-J rearrangements occur. In humans, about $40 \%$ of expressed antibodies contain lambda light chains (9). $V_{H}$ and $V_{L}$ gene segments encode three framework regions (FR1, FR2, and FR3), which are separated by two highly variable domains, termed complementarity determining regions (CDRs). The regions of the $\mathrm{V}_{\mathrm{H}^{-}}$ $D_{H}-J_{H}$ and $V_{L}-J_{L}$ joins define the heavy and light chain CDR3 intervals, respectively, which are at the center of the antigen-binding site (10) and are usually directly involved in antigen binding.

Non-germline-encoded $(\mathrm{N})$ nucleotides are added at the $D_{H} \rightarrow J_{H}$ and $V_{H} \rightarrow D_{H}$ junctions of immunoglobulin heavy chains by the enzyme deoxynucleotidyl transferase (TdT). Until recently, expression of TdT was thought to be restricted to the pro-B-cell stage of $\mathrm{B}$-cell development, when most heavy-chain rearrangement occurs (11). However, we and others have shown that $\mathrm{N}$-region addition can occur in $\mathrm{V} \kappa-\mathrm{J} \kappa$ joins of B cells of normal individuals $(12-16)$ and patients with RA $(17,18)$. As was the case with kappa light chains until recently, $\mathrm{N}$-region addition is not thought to occur in V-J joins of lambda light chains (19), but this issue has not been formally addressed. Sequencing of the human lambda locus $(20,21)$ has made such analysis feasible by allowing assignment of $\mathrm{V}$ and $\mathrm{J}$ gene segment progenitors.

Although N-region addition can occur in kappa light chains, the length of the CDR3 intervals is highly regulated in humans, with $>95 \%$ of sequenced kappa chain CDR3s from normal peripheral B cells having either 9 or 10 amino acids (10). We have shown that in some RA patients, the kappa light repertoire is enriched for unusually long CDR3 intervals
$(16,22)$. This finding may be due to differences in regulation of gene rearrangement, for example, prolonged expression of $\mathrm{TdT}$, or to antigenic selection of $\mathrm{B}$ lymphocytes expressing unusual antibodies.

The goals of the present study were to determine the degree of $\mathrm{N}$-region addition and CDR3-length heterogeneity in lambda light chains expressed in RA patients and normal controls. We focused on expression of the largest $\mathrm{V} \lambda$ family, V $\lambda$ III (21), which is frequently used in autoantibodies from patients with RA (23-26). To avoid potential bias in the results by selecting for antibodies that express a particular reactivity, we used a reverse transcription-polymerase chain reaction (RT-PCR) approach on unsorted cells from synovial tissue and peripheral blood lymphocytes (PBL) of two patients with RA and PBL of three normal controls. $\mathrm{V} \kappa-\mathrm{J} \kappa$ joins expressed in these same samples have been extensively characterized, which allowed comparison of findings in the kappa and lambda repertoires.

We report analysis of a total of $194 \mathrm{~V} \lambda$ sequences-161 cDNA sequences and 33 unrearranged genomic DNA sequences (derived from 6 germline $V \lambda$ III gene segments). Extensive $\mathrm{N}$-region addition was found in the $\mathrm{V} \lambda-\mathrm{J} \lambda$ joins of both RA patients and normal controls. Surprisingly, two of three normal individuals exhibited more $\mathrm{N}$-region addition in lambda light chains than in kappa light chains. The lambda repertoires of the RA patients were enriched for unusually long CDR3 intervals, similar to the pattern previously reported for their kappa repertoires. The CDR3 lengths of lambda light chains in both RA and normal individuals were affected by both $\mathrm{N}$-region addition and by the length of the $\mathrm{V} \lambda$ gene segment utilized in the rearrangement. The enrichment for uncommon CDR3 structures and evidence of oligoclonal B cell expansion in RA provides further support for the hypothesis that changes in the repertoire reflect selection by an unknown antigen or sets of antigens.

\section{Materials and Methods}

Patient Characteristics and Isolation of Synovial Cells and Peripheral Blood Mononuclear Cells

Clinical characterization of the RA patients (BC and AS) and normal controls used in this study and the methods used to process the synovial tissue and peripheral blood have been reported 
previously $(16,17)$. Patients $B C(62, W F)$ and AS $(42, \mathrm{BF})$, as well as normal controls LB (36, WM), LK (23, WF), and IT (62, WF) have been subjects of in-depth analysis of $\mathrm{V}$ gene segment utilization, N-region addition, and CDR3length variability of the kappa light chain repertoire $(16,17,27)$. Synovial tissue and PBL were obtained from AS in close temporal proximity. In this study, PBL from patient BC were obtained several years after isolation of synovial tissue because the supply of RNA from PBL obtained at the time of surgery had been exhausted.

Generation of $c D N A$ and PCR Amplification of $V \lambda$ containing Transcripts

Total RNA was isolated from each sample using the guanidinium isothiocyanate technique (28) or using Tri-Reagent (Molecular Research Center, Inc., Cincinnati, OH). Oligo d(T)primed first-strand cDNA was generated from total RNA as previously described (16). PCR amplifications were performed on 2- $\mu$ l aliquots of first-strand cDNA, using Taq DNA polymerase as previously described (16). PCR conditions were as follows: 30 cycles of denaturation at $94^{\circ} \mathrm{C}$ for $1 \mathrm{~min}$, annealing at $50^{\circ} \mathrm{C}$ for $2 \mathrm{~min}$, extension at $72^{\circ} \mathrm{C}$ for $4 \mathrm{~min}$, with a final extension at $72^{\circ} \mathrm{C}$ for $10 \mathrm{~min}$. A low annealing temperature was used to decrease the likelihood that mutated sequences would be missed.

The V VIII family contains three subfamilies defined serologically and by sequence analysis $(21,29-31)$. Thus, three separate PCR amplifications were performed on each tissue sample to enrich for sequences containing V $\lambda$ IIIa-, V VIIIb-, and VAIIIc-derived gene segments. The three sense primers used were derived from germline leader sequences and were each used in conjunction with an antisense consensus $C \lambda$ primer, LB69. Leader sequences used were LB-75 (V $\lambda$ IIIIa),

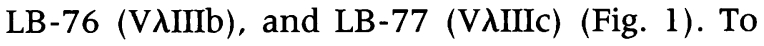
control for possible contamination, mock PCR reaction mixtures lacking template or containing products of the first-strand cDNA reaction without reverse transcriptase were prepared. None of the controls contained amplified product as assessed by ethidium-stained agarose gel electrophoresis or Southern blot analysis using a ${ }^{32} \mathrm{P}$ labeled internal $\mathrm{C} \lambda$ oligonucleotide, LB-70 (Fig. 1).
Isolation of Genomic DNA from non-B Cells and Amplification of Germline $V \lambda$ Gene Segments

In an attempt to allow definitive assignment of cDNA sequences to germline progenitor gene segments, we sequenced unrearranged V $\lambda$ III gene segments from genomic DNA of $\mathrm{T}$ lymphocytes from two individuals (RA patient $B C$ and normal control LB). PBL were obtained by standard Ficoll-Hypaque gradient centrifugation (32). T lymphocytes were isolated from PBL by sheep red blood cell (SRBC) rosetting (33). Briefly, $1 \mathrm{ml}$ of $25 \% 2$-aminoethylisothiouronium bromide (AET)-SRBC was added per $10^{8} \mathrm{PBL}$. The PBLs were resuspended in $\sim 10 \mathrm{ml} 5 \%$ fetal calf serum (FCS) $/ 10^{8}$ PBL. The PBL-SRBC solution was distributed evenly into sterile round-bottom $15-\mathrm{ml}$ tubes and centrifuged for $5 \mathrm{~min}$. The tubes were placed on ice for $30 \mathrm{~min}$, then the pellets were resuspended in ice cold 5\% FCS. Aliquots of $40 \times$ $10^{6}$ cells were pipetted onto Ficoll-Hypaque and centrifuged at $1800 \mathrm{rpm}$ at $4^{\circ} \mathrm{C}$ for $30 \mathrm{~min}$. The interface, which contained the B lymphocytes, was removed. The $\mathrm{T}$ cells in the pellet were then washed three times and genomic DNA was extracted, purified by phenol extraction, and precipitated in ethanol using standard techniques (34).

PCR amplifications were performed on $2-\mu l$ aliquots of genomic DNA. PCR conditions were as follows: preheat to $94^{\circ} \mathrm{C}$ for $2 \mathrm{~min}$, followed by 35 cycles of denaturation at $94^{\circ} \mathrm{C}$ for $30 \mathrm{sec}$, annealing at $50^{\circ} \mathrm{C}$ for $30 \mathrm{sec}$, extension at $72^{\circ} \mathrm{C}$ for $1 \mathrm{~min}$, with a final extension at $72^{\circ} \mathrm{C}$ for $7 \mathrm{~min}$. Two separate PCR amplifications were performed on each genomic DNA, one to amplify V $\lambda$ IIIIa and V $\lambda$ IIIc gene segments (using upstream primer LB-123 and downstream primer LB-125), and one to amplify V $\lambda$ IIIlb gene segments (using upstream primer LB-124 and downstream primer LB-125) (Fig. 1). Primer LB-123 was derived from the intronic sequences of the V $\lambda$ IIIa gene segments IGLV3S2 (35) and humlv318 (29), and the V $\lambda$ IIIC gene segment III.1 (30). Primer LB-124 was derived from intron sequences from the V VIIIb gene segments hsiggll150 (26) and hsiggll295 (26). Primer LB-125 was derived from the heptamer, 23 base pair spacer, and nonamer sequences of the recombination signal sequences (RSS) of the IGLV3S2, humlv318, and III.l gene segments (Fig. 1C). PCR products were probed with an internal probe, LB-126, derived from a portion of the 


\begin{tabular}{|c|c|c|c|c|}
\hline Primer & Gene & Region & Orientation & Sequence $\left(5^{\prime} \rightarrow 3^{\prime}\right)$ \\
\hline LB-75 & VגIIIa & Leader & Sense & TCCGAATTCTCCTCTCTCACTGCACAG \\
\hline LB-76 & VגIIIb & Leader & Sense & TCCGAATTCTCTGCACAGTCTCTGAGGCC \\
\hline LB-77 & VגIIIc & Leader & Sense & CCCTGAATTCCTCGGCGTCCTTGCTTACTGCA \\
\hline LB-69 & $\mathrm{C} \lambda$ & Constant & Antisense & GGGAATTCGCTCCCGGGTAGAAGTCACT \\
\hline LB-70 & $\mathrm{C \lambda}$ & Internal & Antisense & GGGAATTCTTG(GA)CTTGGAGCTCCTCAGAGGAGGG \\
\hline LB-123 & $\mathrm{V \lambda IIIa/c}$ & Intron & Sense & TCCAGC(CG)TG(GT)CC(CT)TGA(CT)TCTGAGCTCAGGA \\
\hline LB-124 & VגIIIb & Intron & Sense & GTGCT(GT)(CT)(CT)CCCAGGCCCTGCTCCAGGC \\
\hline LB-125 & VגIII & RSS & Antisense & (GT)GTTT(CT)TGTCTCACTTCC(GT)CATCTGCCTGTGT(CT)AC(CT)GTG \\
\hline LB-126 & VAIII & FR2 & Sense & CAGCAGAAGCCAGGCCAG \\
\hline
\end{tabular}

\section{B}

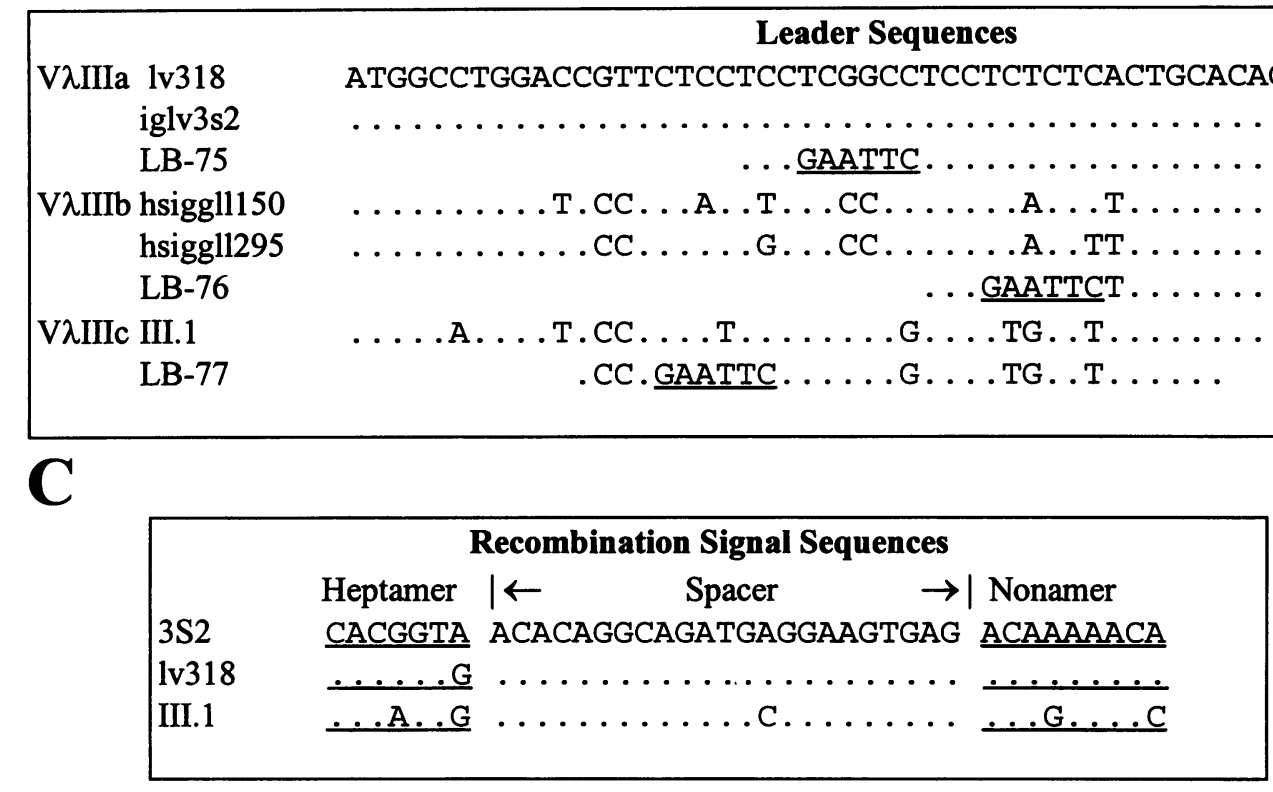

Fig. 1. (A) Sequences of oligonucleotides used as primers and probes. Parentheses indicate sites of degeneracy. RSS, recombination signal sequence; FR2, framework 2. (B) Comparison of V VIIIa, b, and $c$ leader sequences and primers used for RT-PCR to

framework 2 domain that is highly conserved among V $\lambda$ III gene segments.

\section{Cloning and Sequencing of PCR Products}

Aliquots of PCR products were subcloned using the TA cloning kit (Invitrogen, San Diego, CA). Plasmids were transformed into INV $\alpha \mathrm{F}^{-}$E. coli by electroporation using a Bio-Rad Gene Pulser (Hercules, CA). For colonies that hybridized to the $C \lambda$ probe, plasmid DNA was obtained and sequenced by the dideoxy chain termination procedure (36) either manually or using an au- the germline humlv318 sequence. Dots indicate nucleotide sequence homology. Underlined sequences indicate EcoRI restriction sites. (C) Sequences of RSS of gene segments IGLV3S2, lv318, and III.1.

tomated sequencer (Applied Biosystems, Inc., Model AB373).

\section{Sequence Analysis}

The FR and CDR domains of each of the sequences were compared individually to corresponding domains of published human $\mathrm{V} \lambda$ sequences using the computer program SAW (Sequence Analysis Workshop) (37). Sequences were assigned to germline gene segments according to highest degree of nucleotide sequence homology. Levels of somatic 
Table 1A. Germline derivation of V $\lambda$ gene segments in cDNA clones from patients with rheumatoid arthritis and normal controls

\begin{tabular}{|c|c|c|c|c|c|c|c|c|c|c|c|c|c|c|c|c|c|c|c|c|}
\hline & \multirow{2}{*}{\begin{tabular}{|l|}
$\mathrm{V} \lambda$ Family \\
Gene Segment \\
\end{tabular}} & \multicolumn{2}{|c|}{$\mathrm{V} \lambda \mathrm{I}$} & \multicolumn{3}{|c|}{ 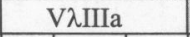 } & \multicolumn{4}{|c|}{ VגIIIb } & \multirow{2}{*}{\begin{tabular}{|c|} 
VגIIIc \\
III.1 \\
\end{tabular}} & \multicolumn{3}{|c|}{ VגIV } & \multicolumn{4}{|c|}{$\mathrm{V} \lambda \mathrm{V}$} & \multicolumn{2}{|l|}{$\mathrm{V \lambda} \mathrm{VI}$} \\
\hline & & Iv1042 & DPL6 & $3 \mathrm{~S} 2$ & $\operatorname{lv} 318$ & $2-14$ & 150 & $3 a$ & $3 p$ & 2-19 & & $8 \mathrm{Al}$ & lv801 & $5-4$ & $5 \mathrm{a}$ & $5 c 1$ & $5 c 2$ & 4-2 & $6 \mathrm{~S} 1$ & Total \\
\hline \multirow[t]{4}{*}{$\mathbf{R A}$} & AS Synovium & 1 & 1 & 5 & 3 & 0 & 10 & 0 & 1 & 1 & 5 & 1 & 1 & 0 & 0 & 1 & 0 & 0 & 1 & 31 \\
\hline & AS PBL & 3 & 0 & 1 & 4 & 0 & 8 & 0 & 0 & 0 & 6 & 0 & 0 & 0 & 0 & 0 & 0 & 0 & 0 & 22 \\
\hline & BC Synovium & 1 & 0 & 4 & 0 & 1 & 4 & 0 & 4 & 0 & 2 & 1 & 0 & 0 & 0 & 0 & 0 & 0 & 4 & 21 \\
\hline & BC PBL & 0 & 0 & 1 & 0 & 2 & 1 & 0 & 5 & 0 & 6 & 0 & 0 & 0 & 1 & 0 & 2 & 1 & 1 & 20 \\
\hline \multirow[t]{4}{*}{ Normal } & LB PBL & 1 & 0 & 0 & 0 & 3 & 6 & 0 & 0 & 0 & 3 & 1 & 0 & 1 & 0 & 1 & 0 & 0 & 2 & 18 \\
\hline & IT PBL & 0 & 0 & 1 & 0 & 5 & 11 & 1 & 0 & 0 & 7 & 1 & 0 & 0 & 1 & 0 & 1 & 0 & 1 & 29 \\
\hline & LK PBL & 2 & 0 & 0 & 0 & 0 & 6 & 0 & 1 & 1 & 7 & 0 & 0 & 1 & 0 & 0 & 2 & 0 & 0 & 20 \\
\hline & Total & 8 & 1 & 12 & 7 & 11 & 46 & 1 & 11 & 2 & 36 & 4 & 1 & 2 & 2 & 2 & 5 & 1 & 9 & 161 \\
\hline
\end{tabular}

Germline gene segments in Table 1A were reported as follows: Iv1042 (42), DPL6 (43), 3S2 (35), lv318 (29), 2-14, 2-19, 4-2, and 5-4 (21), hsiggll150 (20,26), 3a, 3p, 5a, 5cl, and 5c2 (20), III.1 (20, 30), 8Al (44), lv801 (45), and 6S1 (46).

hypermutation were assessed by comparing the FR1 through the FR3 domains (codons 1-88 according to ref. 10) of each complete transcript to the appropriate germline sequence and calculating mean divergence for each sample. Truncated clones were not included in the somatic mutation analysis.

$P$ nucleotides are nucleotides that are palindromic to terminal nucleotides of coding sequences (38). They are inserted adjacent to the corresponding coding sequences at the junction of rearranged gene segments and are thought to be a consequence of the resolution of hairpin structures that occur during $V(D) J$ recombination (39). In this study, nucleotide mismatches at the $3^{\prime}$-end of the $V \lambda$ gene segment or the $5^{\prime}$-end of the $J \lambda$ gene segment that did not appear to be palindromic to the $\mathrm{V}$ or $\mathrm{J}$ were assumed to represent $\mathrm{N}$-region addition rather than somatic mutation. In order to allow valid comparisons between lambda and kappa chains expressed in the same samples, sequences of previously reported $\mathrm{V} \kappa-\mathrm{J} \kappa$ joins (16) were reanalyzed to look for the presence of $\mathrm{P}$ nucleotides.

\section{Statistical Analysis}

Differences in the amount of somatic mutation, $\mathrm{N}$-region addition, and CDR3-length heterogeneity between patients with RA and normal individuals were analyzed using the Chi-square test, Fisher exact test (two-tailed), or Student $t$-test, as appropriate. Three-way comparisons were performed using analysis of variance (ANOVA).

\section{Results \\ Germline Vג Gene Segment Derivation of CDNA Sequences}

In humans, there are three separate clusters of $\mathrm{V} \lambda$ gene segments on chromosome 22q11.2 (40). There are a total of $\sim 69 \mathrm{~V} \lambda$ gene segments, including $\sim 36$ functional $\mathrm{V} \lambda$ gene segments and $\sim 33$ pseudogenes, which are grouped into 10 families on the basis of nucleotide sequence homology $(20,21)$. Two gene segments that are not part of the major locus, so-called orphon sequences, have been reported on chromosome 8q11.2 (41). Allelic polymorphism of the human lambda locus appears to be limited (20). As mentioned above, the V $\lambda$ III family is the largest V $\lambda$ family, composed of 10 functional members and 13 pseudogenes, which are subdivided into three subgroups (a, b, and c) (21,29-31).

The $V \lambda$ gene segments of 161 cDNA clones were assignable to known germline gene segments (Table 1A). Of 10 V $\lambda$ III germline gene segments with open reading frames $(20,21)$, 123 of $126(97.6 \%)$ V $\lambda$ III transcripts were derived from six gene segments: V $\lambda$ IIIa gene segments IGLV3S2 (35) (12 clones, $7.5 \%$ of the total), 2-14 (21) (11 clones, 6.9\%), and humlv318 (29) (7 clones, 4.4\%); V $\lambda$ IIIb gene segments hsiggll50 (3m) $(20,26)$ (46 clones, $28.8 \%$ ) and $3 p$ (20) ( 11 clones, $6.9 \%$ ); and VAIIIc gene segment III.l (3r) $(20,30) \quad(35$ clones, $21.9 \%$ ). This pattern of V $\lambda$ III gene utilization is similar to that found by other investigators, who assessed the expression of $\mathrm{V} \lambda$ 
gene segments by screening cDNA libraries generated from normal PBL (47). In that study, the most commonly expressed V $\lambda$ III gene segments were $3 \mathrm{~h}$ (which includes closely related gene segments IGLV3S2, humlv318, and 2-14; ref. 20), 3r (III.1), 3p, and 3m (hsiggll 150), with less frequent representation of $3 e, 31,3 a$, and $3 \mathrm{j}$. In the present study, because of crossreactivity of the PCR primers, members of the $\mathrm{V} \lambda \mathrm{I}$ (9 clones, $5.6 \%)$, V $\lambda \mathrm{IV}$ (8 clones, $5.0 \%$ ), $\mathrm{V} \lambda \mathrm{V}$ (10 clones, $6.3 \%)$, and V $\lambda$ VI (9 clones, $5.6 \%)$ families were also represented.

Several clones were found to have deletions or insertions in the $\mathrm{V}$ gene segment (Figs. 2 and 3). ASSynL191 had a three-nucleotide deletion in CDRl and LKPBLL68 contained a three-nucleotide insertion in CDR1. LKPBLL10 had one nucleotide missing from FR2 and a one-base pair insertion in the CDR3 interval. ITPBLL75 contained a ten-base pair deletion at the FR3-CDR3 junction. Single base pair insertions in CDR3 were seen in clones LBPBLL4, ITPBLL4, and LKPBLL53. Overall, there were 5 out-of-frame cDNA sequences, all of which were isolated from normal PBL.

\section{Derivation of Unrearranged $V \lambda$ Gene Segments Amplified from $T$ Lymphocytes}

Of 33 clones from two different individuals (RA patient BC and normal control LB), six different gene segments [3i, hsiggll $150(3 \mathrm{~m})$, $3 a, 3 p$, III.l (3r), and 3e] were represented (Table 1B). Thirty-one of $33(94 \%)$ of the clones were $100 \%$ identical to known germline gene segments. Clone LBLG9 was found to have two nucleotide differences from the reported $3 p$ sequence: GGG instead of GAG at codon 50 in CDR2, resulting in a glycine residue instead of glutamine, and ATG instead of GTG at codon 80 in FR3, resulting in a methionine residue rather than a valine. Clone LBLB 14 had three nucleotide differences from the reported III.1 sequence: ACG instead of ACA at codon 18 in FRl, which does not change the encoded threonine residue, GCA instead of ACA at position 70 in FR3, resulting in alanine instead of threonine, and GTT (Val) instead of GCT (Ala) at codon 80 in FR3. None of the clones reported here appeared to be derived from these two variant sequences. One or more of these five sequence changes may represent PCR artifact induced by Taq DNA polymerase (see below).

\section{Possible Allelic Variants of $V \lambda$ Gene Segments}

Among the cDNA sequences, we found multiple sets of clones that had shared differences in the $\mathrm{V} \lambda$ gene segments (Table 2) but were definitely not clonally related, as they utilized different $J \lambda$ gene segments or had discordant $\mathrm{N}$-region addition and/or CDR3 lengths (Fig. 3). This finding suggests the presence of novel allelic variants of germline gene segments IGLV3S2, III.1, hsiggll150, and iglv6S1, or the presence of novel gene segments closely related to those germline genes. In the sequence analysis of unrearranged gene segments (see above), we did not isolate germline sequences containing the variant codons shown in Table 2. Possible explanations for this discrepancy are the small number of genomic sequences we analyzed or sequence mismatches between our PCR primers and intronic sequences of allelic variants.
Fig. 2. Deduced amino acid sequences of $\mathbf{V} \boldsymbol{\lambda}$ CDNA clones from RA synovia, RA PBL, and normal PBL. Dots indicate sequence homology; single-letter amino acid abbreviations are used, $\mathrm{X}$, stop codon in deduced amino acid sequence. *, termination of cDNA transcript. $\ddagger$, Clone BCSynL 32 contains FRl and CDRl domains from V $\lambda$ gene segment $6 \mathrm{~S} 1$ and FR2 through CDR3 domains from $\mathrm{V} \lambda$ gene segment DPL8. §, Clones containing insertions or deletions: ASSynL191 has a three-nucleotide deletion in CDR1, denoted by dash; ASPBLL54 has a two-base pair deletion in FRl; ITPBLL4 has a onenucleotide insertion in the CDR3 interval; ITPBLL75 contains a 10-nucleotide deletion at the FR3-CDR3 junction; LBPBLL4 has a one-nucleotide insertion in
CDR3; LKPBLL10 contains a one-nucleotide deletion in FR2 and a one-nucleotide insertion (or a two nucleotide deletion) in CDR3; LKPBLL53 has a onenucleotide insertion (or a two nucleotide deletion) in the CDR3 interval; LKPBLL68 has a three-nucleotide (one codon) insertion in CDRl. I, Clone BCSynL 38 contains a stop codon in FR2. Genbank accession numbers for nucleotide sequences are as follows: AS Synovium: AF060120-AF060150; AS PBL: AF058057-AF058078; BC Synovium: AF063714-AF063734; BC PBL: AF063694AF063713; IT PBL: AF063735-AF063762; LB PBL: AF063765-AF063782; LK PBL: AF064494AF064513. 

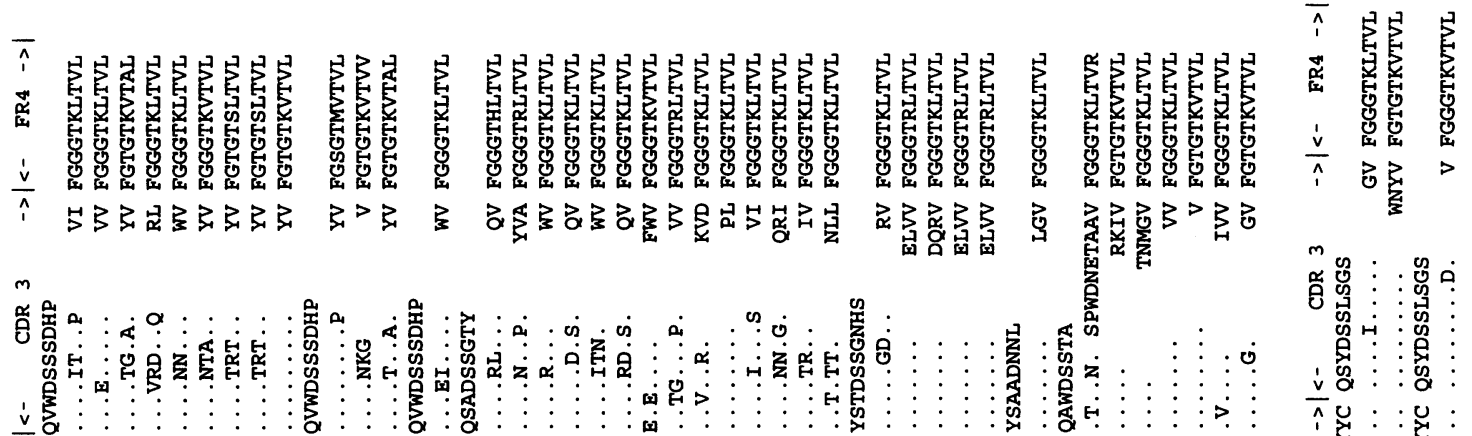

m<smiles>[B]1C=C[As]1</smiles>

谒嗾

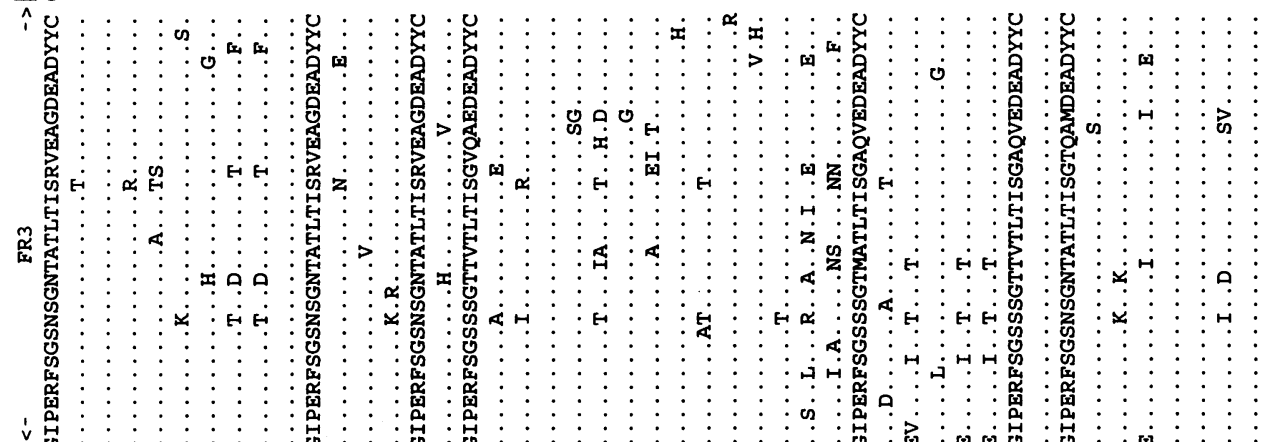

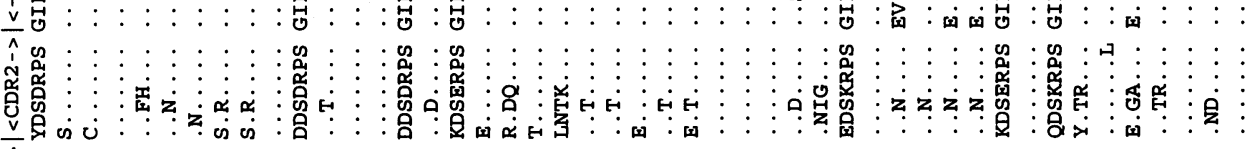

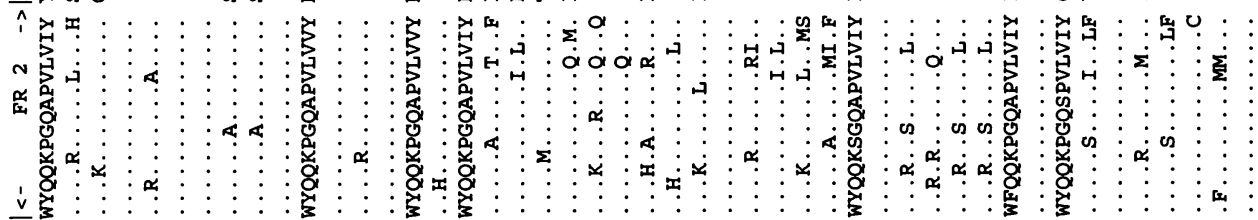

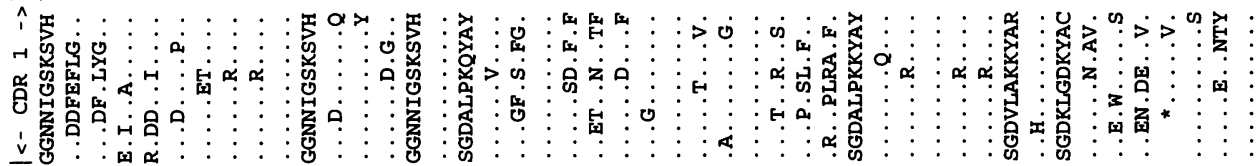

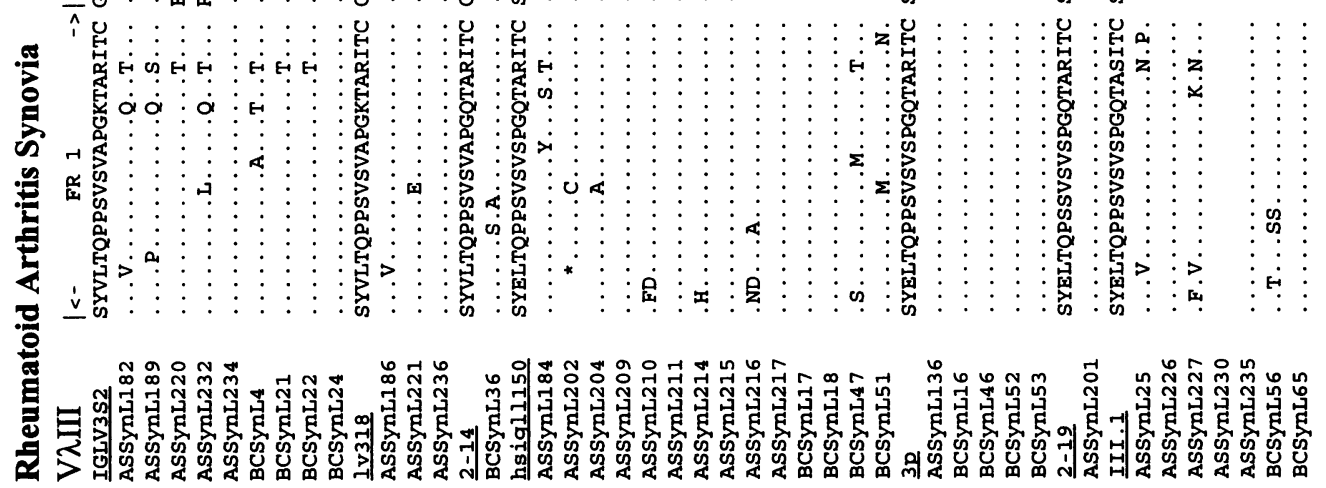

î

要暴

政

:

器:

of

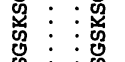

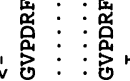

त्र

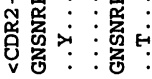

邻 : :

2
2

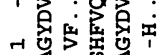

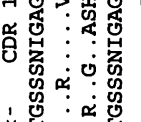

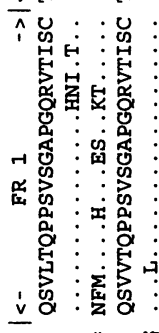

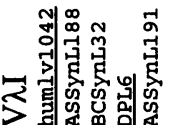




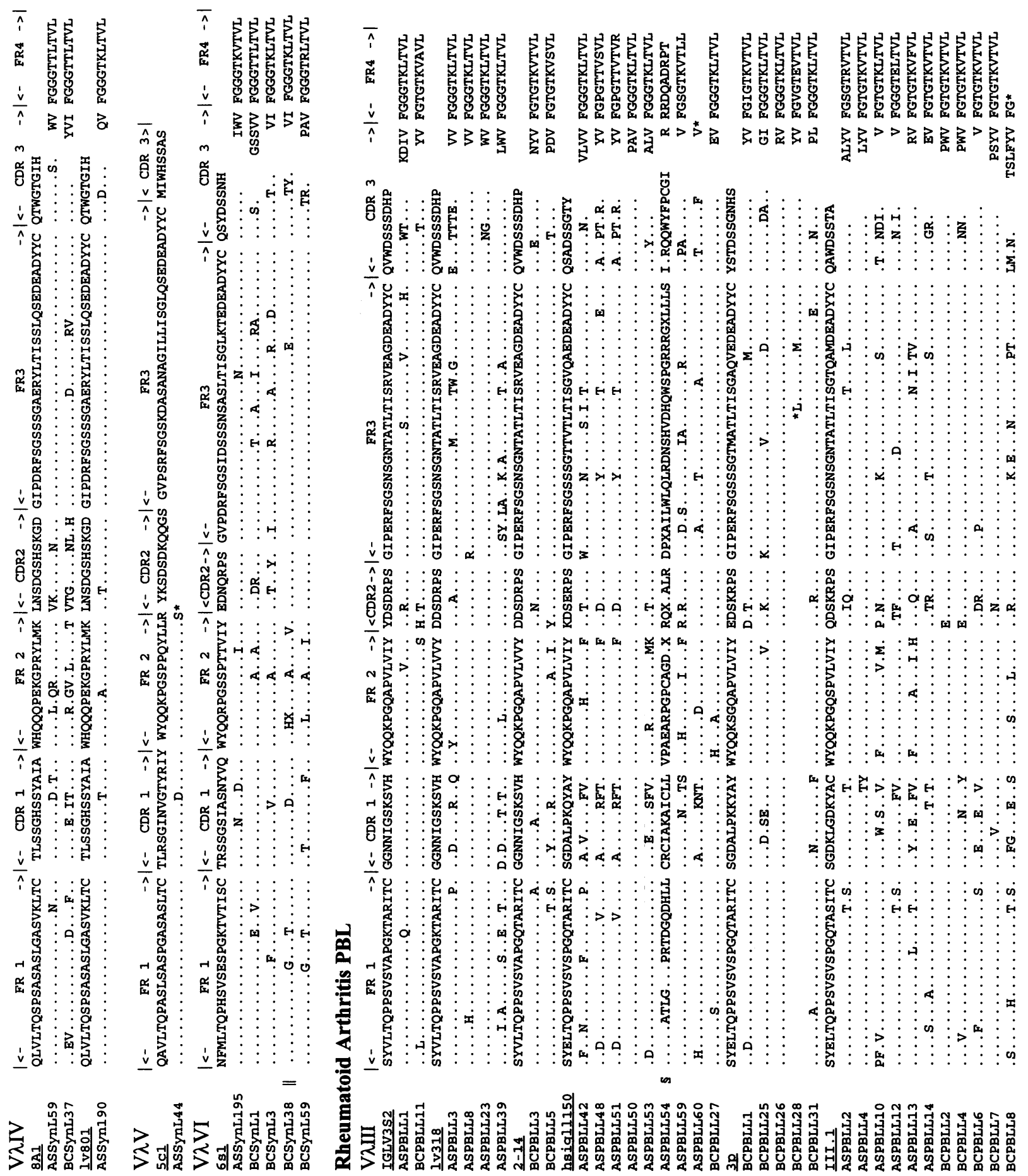

Fig. 2 (Continued)

The presence of sequence variations that could represent allelic variants was not unexpected, as differences have been found in several germline V VIII gene segments from different individuals. These include the germline gene segments 3p/hsiggll295 (4 nucleotide differences) and $3 \mathrm{~m} / \mathrm{hsiggll} 150$ (3 nucleotide differences) (20). An informative example is the case of the closely related sequences humlv318 (29), 2-14 (21), and IGLV3S2 (35). The humlv318 and 2-14 gene segments differ by only one nucleotide in the coding sequence and are 4 nucleotides and 5 


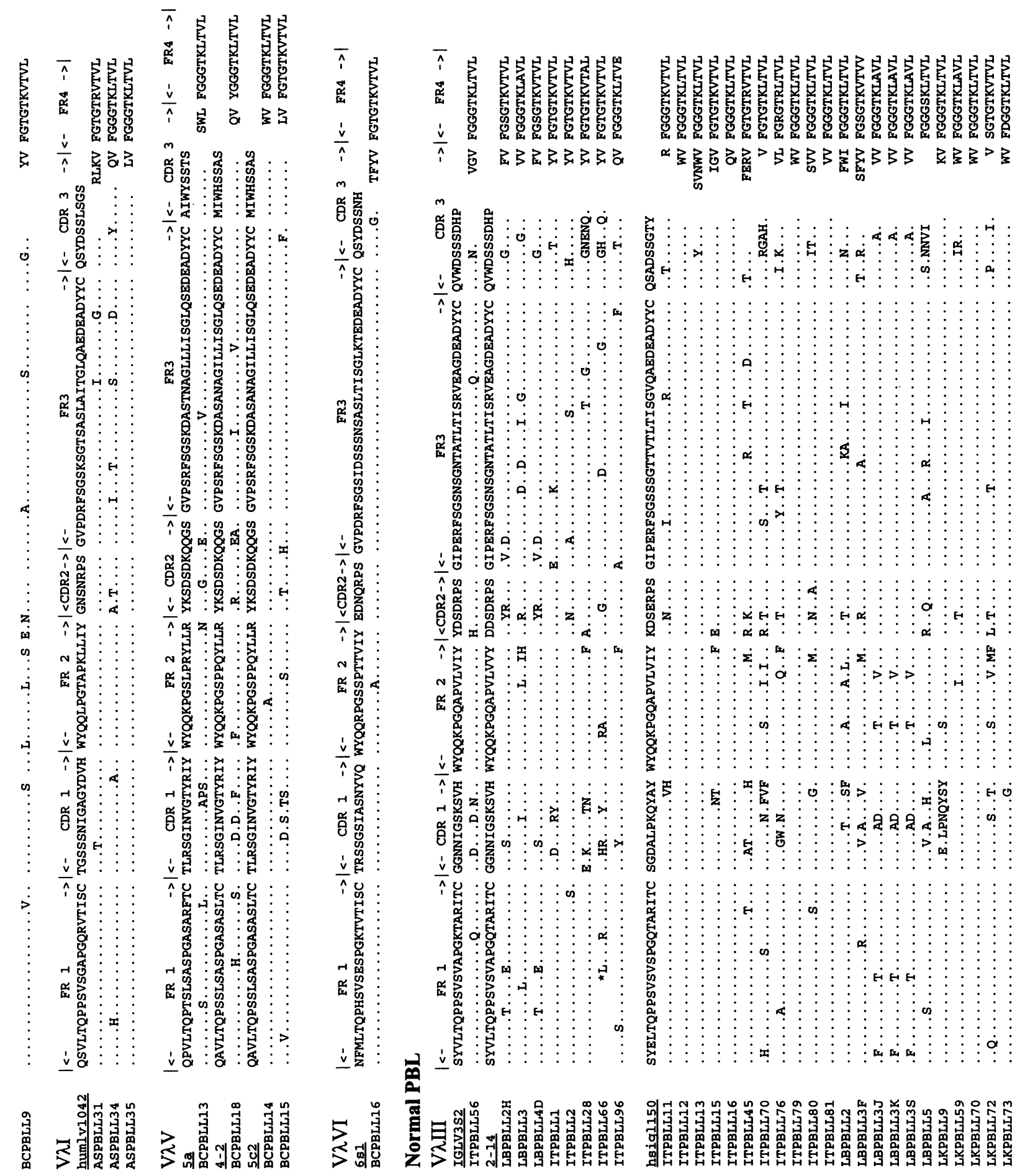

Fig. 2 (Continued)

nucleotides different from the IGLV3S2 gene segment, respectively. The finding that the humlv318 (3h) and 2-14 gene segments are located in the same position in the lambda locus on chromosome $2 q 11.2$ in mapping studies $(21,40)$ suggests that they represent allelic variants of the same gene segment. The fact that none of the five individuals in this study expressed both humlv318 and 2-14 (Table 1A) provides further support for this hypothesis. 


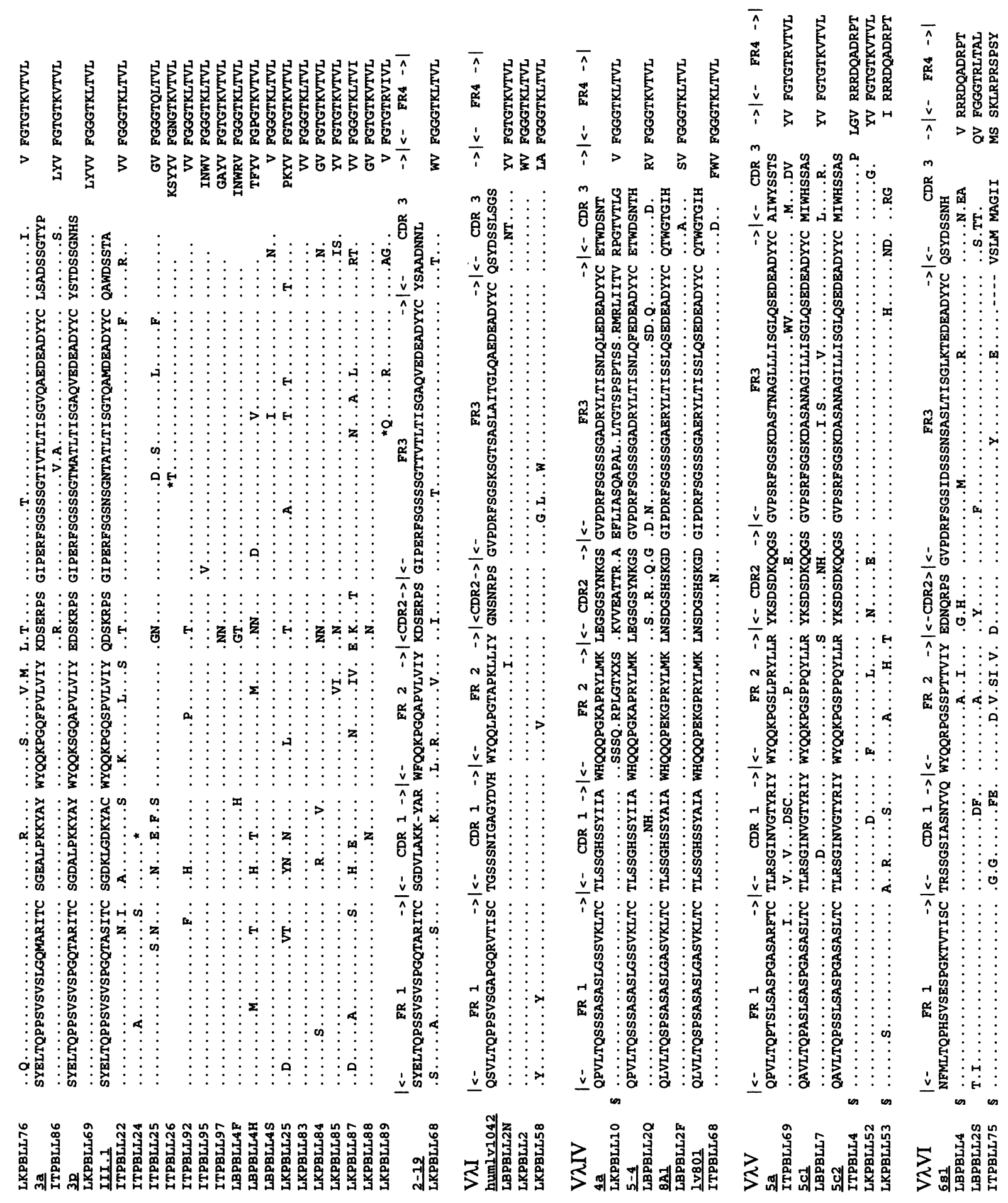

Fig. 2 (Continued)

Variability of $J \lambda$ Gene Segment Expression in $R A$, and Expression of a Recently Described J 3 Allelic Variant

In humans, there are four functional $\lambda$ isotypes encoded by the $C \lambda 1, C \lambda 2, C \lambda 3$, and $C \lambda 7$ genes, each with its own $J \lambda$ gene segment $(21,48)$. Although the $\mathrm{J} \lambda 1, \mathrm{~J} \lambda 2, \mathrm{~J} \lambda 3$, and $\mathrm{J} \lambda 7$ gene segments $(49-51)$ are the only expressed $\mathrm{J} \lambda$ gene segments, $J \lambda 6$ is potentially functional (52). The $J \lambda 2$ and $J \lambda 3$ gene segments have previ- 


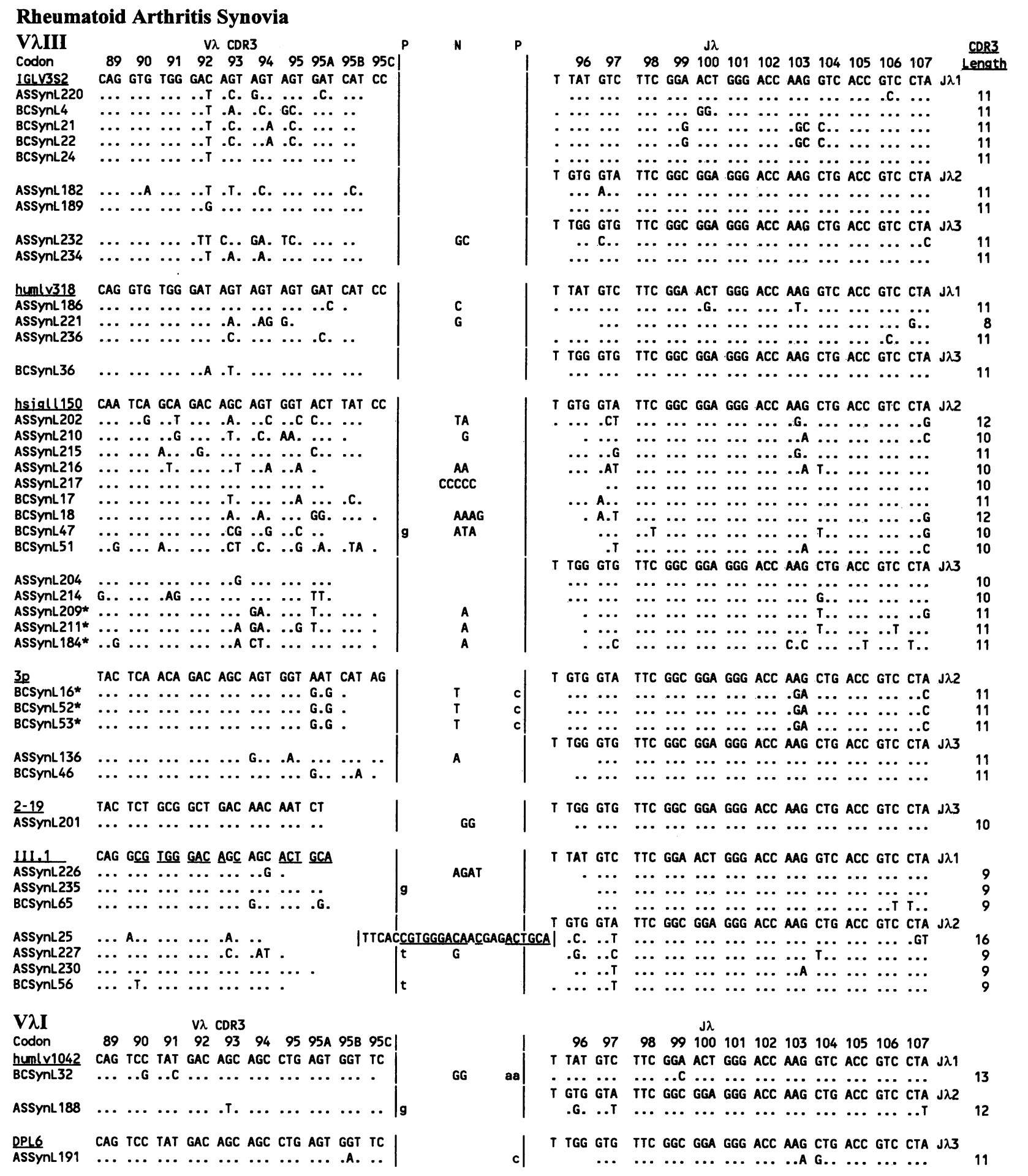

Fig. 3. Nucleotide sequences of $V \lambda-J \lambda$ joins of cDNA clones amplified from RA synovia, RA PBL, and normal PBL. Dots indicate sequence homology. Palindromic (P) nucleotides are shown in lower-case letters. *, related sequences (see text for details). Clone BCPBLL8 is truncated in the $J \lambda$ gene segment. §, Clones with insertions in CDR3 intervals: LKPBLL10 contains a one-nucleotide deletion in FR2 and a one-nucleotide insertion in CDR3; LK-
PBLL53, ITPBLL4, and LBPBLL4 contain single nucleotide insertions in CDR3 intervals. The sequence at the $\mathrm{V} \lambda-\mathrm{J} \lambda$ join in ASSynL25 may represent an insertion event from codons 89 through $95 \mathrm{~A}$ of the germline V $\lambda$ III.1 CDR3 component. Nucleotides shared by the junctional sequence of ASSynL25 and germline VAIII.l are underlined (see Discussion for details). The number of codons in CDR3 intervals are shown. 


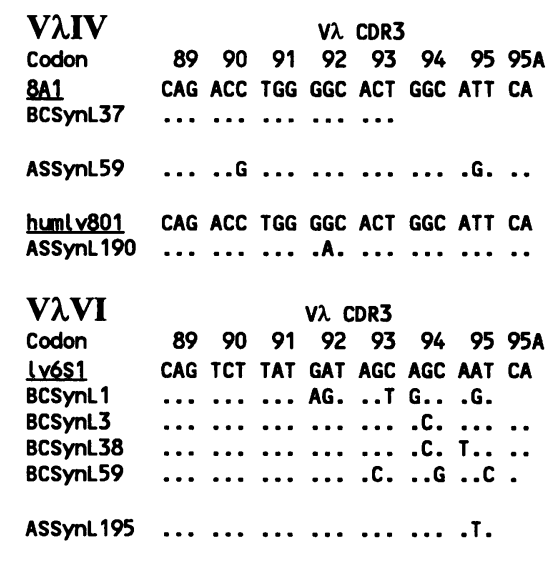

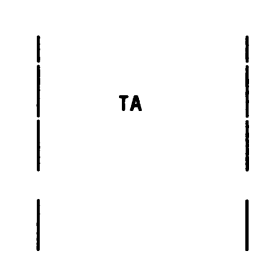

$\begin{array}{llllllllllll}96 & 97 & 98 & 99 & 100 & 101 & 102 & 103 & 104 & 105 & 106 & 107\end{array}$ T GTG GTA TTC GGC GGA GGG ACC AAG CTG ACC GTC CTA J J2

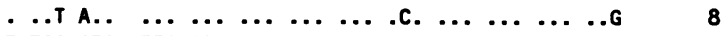
\begin{tabular}{lllllll}
\hline T TGG GTG TTC GGC GGA GGG ACC AAG CTG ACC GTC CTA J J 3 \\
$\ldots$ \\
$\ldots$
\end{tabular} T TGG GTG TTC GGC GGA GGG ACC AAG CTG ACC GTC CTA J $\lambda 3$

$\begin{array}{llllllllllllll} & \ldots & \ldots & \ldots & \ldots & \ldots & \ldots & \ldots & \ldots & \ldots & \ldots & \ldots & \ldots & \ldots\end{array}$

$J \lambda$

$\begin{array}{llllllllllll}96 & 97 & 98 & 99 & 100 & 101 & 102 & 103 & 104 & 105 & 106 & 107\end{array}$ T GTG GTA TTC GGC GGA GGG ACC AAG CTG ACC GTC CTA J J2

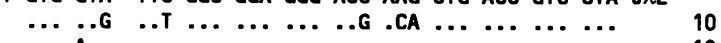

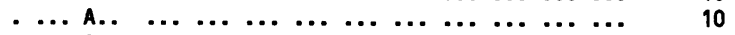
$\begin{array}{llllllllllllll} & \ldots & \text { A.. } & \ldots & \ldots & \ldots & \ldots & \ldots & \ldots & \ldots & \ldots & \ldots & \ldots & \ldots\end{array}$ ; T TGG GTG TTC GGC GGA GGG ACC AAG CTG ACC GTC CTA J $\lambda 3$

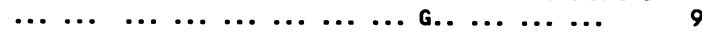

\section{Rheumatoid Arthritis PBL}

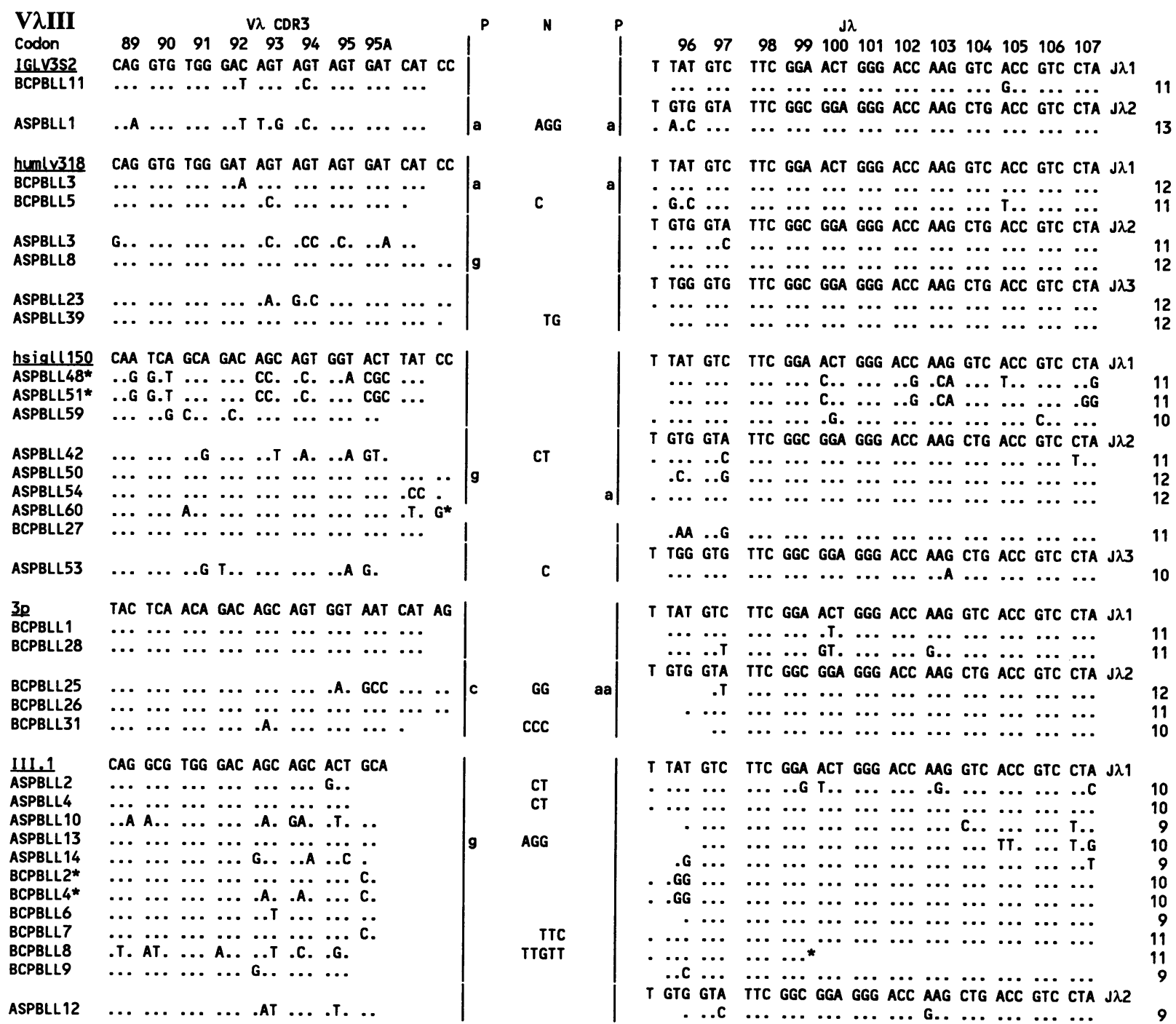

Fig. 3. (Continued) 


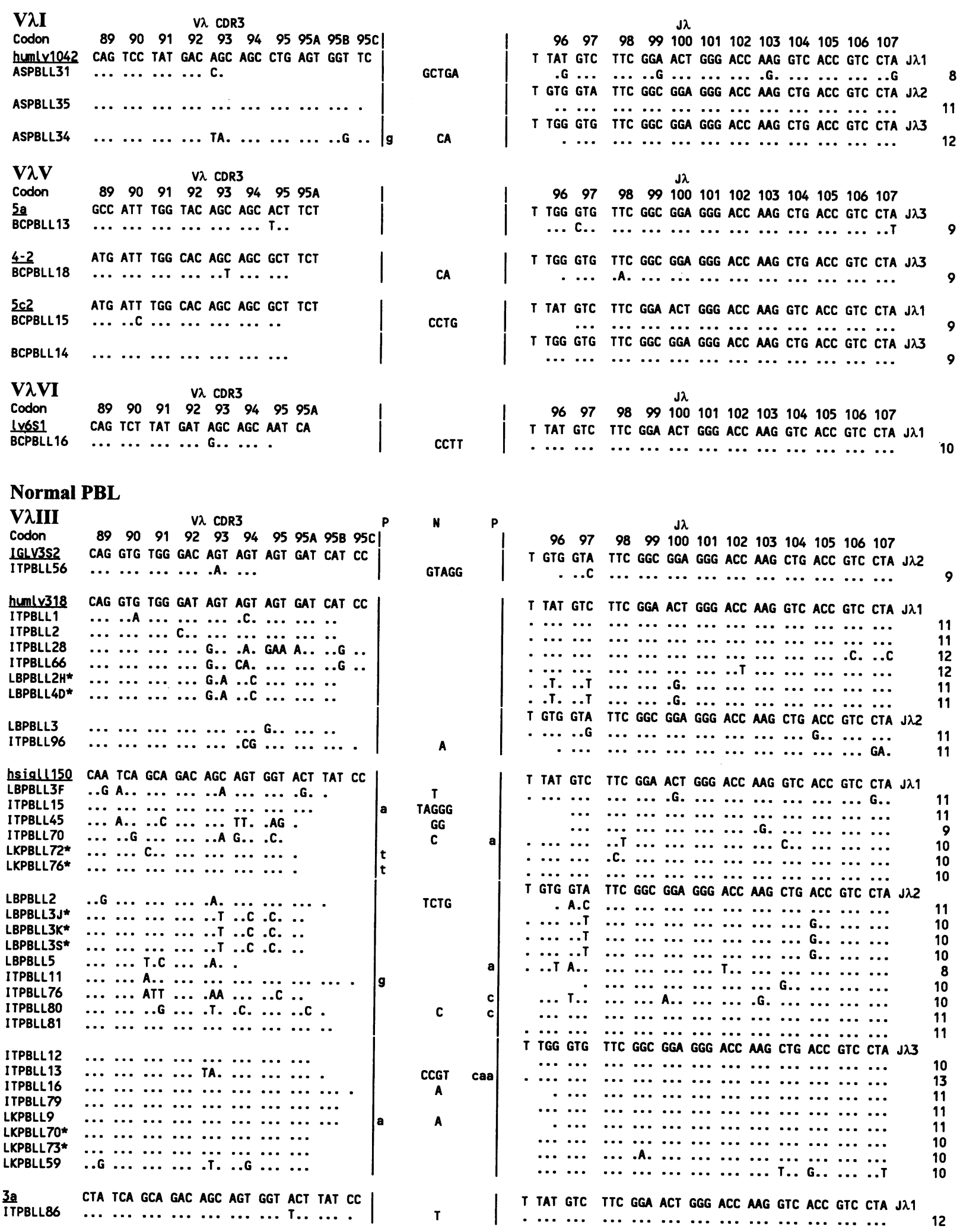

Fig. 3. (Continued) 


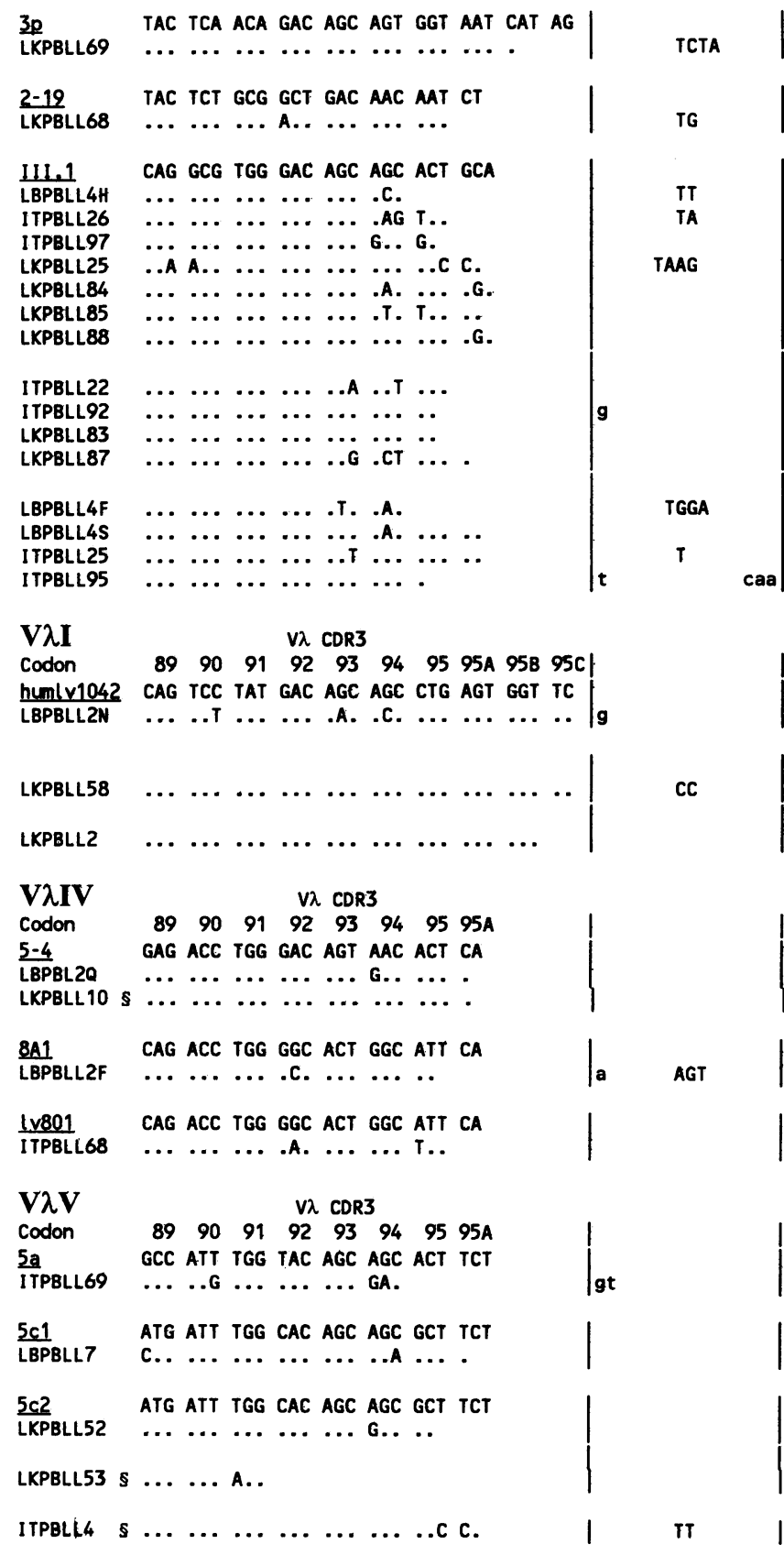

T GTG GTA TTC GGC GGA GGG ACC AAG CTG ACC GTC CTA J J2

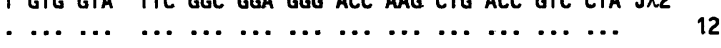

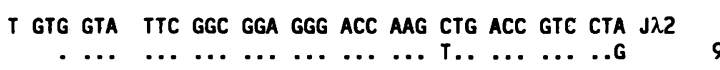

T TAT GTC TTC GGA ACT GGG ACC AAG GTC ACC GTC CTA JA1

. ... ... $\ldots . . .$.

$\begin{array}{lllllllllllll} & \ldots & \ldots & \ldots & \ldots & \text {.А. } & \ldots & \ldots & \ldots & \ldots & \ldots & \ldots & \ldots\end{array}$

$\begin{array}{lllllllllllll} & \ldots & \ldots & \ldots & \ldots & \ldots & \ldots & \ldots & \ldots & \ldots & \ldots & \ldots & \ldots\end{array}$

$\cdots \cdots \cdot$

$\begin{array}{llllllllllll} & \ldots & \ldots & \ldots & \ldots & \ldots & \ldots & \ldots & \ldots & \ldots & \ldots & \ldots\end{array}$

$\begin{array}{lllllllllllll} & \cdots & \cdots & \cdots & \cdots & \cdots & \cdots & \cdots & \cdots & \cdots & \cdots & \cdots & \cdots\end{array}$

T GTG GTA TIC GGC GGA GGG ACC AAG CTG ACC GTC CTA J 22

$\begin{array}{lllllllllllll}\cdots & \cdots & \cdots & \ldots & \ldots & \ldots & \ldots & \ldots & \ldots & \ldots & \ldots & \ldots\end{array}$

$\begin{array}{lllllllllllll}\cdots & \cdots & \cdots & \cdots & \cdots & \cdots & \cdots & \cdots & \cdots & \cdots & \ldots & \cdots & q\end{array}$

$\begin{array}{lllllllllllll}\cdots & \cdots & \cdots & \cdots & \cdots & \cdots & \cdots & \cdots & \cdots & \cdots & \cdots & \cdots & 9\end{array}$

T TGG GTG TTC GGC GGA GGG ACC AAG CTG ACC GTC CTA J $\lambda 3$

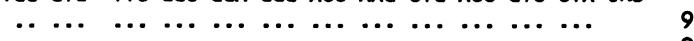

$\begin{array}{lllllllllllll} & \ldots & \ldots & \ldots & \ldots & \ldots & \ldots & \ldots & \ldots & \ldots & \ldots & \ldots & \end{array}$

$\begin{array}{llllllllllllll}\ldots & \ldots & \ldots & \ldots & \ldots & \ldots & \ldots & \ldots . A & \ldots & \ldots & \ldots & \ldots & \ldots & 10\end{array}$

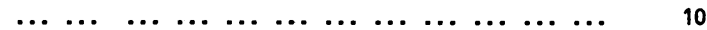

$\mathrm{J} \lambda$

$\begin{array}{llllllllllll}96 & 97 & 98 & 99 & 100 & 101 & 102 & 103 & 104 & 105 & 106 & 107\end{array}$

T TAT GTC TTC GGA ACT GGG ACC AAG GTC ACC GTC CTA J $\lambda 1$

$\begin{array}{llllllllllll} & \ldots & \ldots & \ldots & \ldots & \ldots & \ldots & \ldots & \ldots & \ldots & \ldots & \ldots\end{array}$

T GTG GTA TTC GGC GGA GGG ACC AAG CTG ACC GTC CTA J 22

$\begin{array}{lllllllllllll} & \ldots . \text {.C. } & \ldots & \ldots & \ldots & \ldots & \ldots & \ldots & \ldots & \ldots & \ldots & \ldots & \ldots\end{array}$

T TGG GTG TTC GGC GGA GGG ACC AAG CTG ACC GTC CTA J $\lambda 3$

$\begin{array}{llllllllllllll} & \ldots & \ldots & \ldots & \ldots & \ldots & \ldots & \ldots & \ldots & \ldots & \ldots & \ldots & \ldots & \ldots\end{array}$

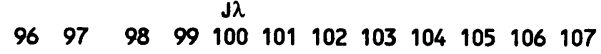

T TGG GTG TTC GGC GGA GGG ACC AAG CTG ACC GTC CTA J $\lambda 3$

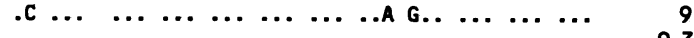

T GTG GTA TTC GGC GGA GGG ACC AAG CTG ACC GTC CTA J $\lambda 2$

$\begin{array}{llllllllll} & \ldots & \ldots & \ldots & \ldots & \ldots & \ldots & \ldots & \ldots & \ldots\end{array}$

T TGG GTG TTC GGC GGA GGG ACC AAG CTG ACC GTC CTA J $\lambda 3$

$\begin{array}{lllllllllllll} & \ldots & \ldots & \ldots & \ldots & \ldots & \ldots & \ldots & \ldots & \ldots & \ldots & \ldots & \ldots\end{array}$

$\begin{array}{llllllllllll}96 & 97 & 98 & 99 & 100 & 101 & 102 & 103 & 104 & 105 & 106 & 107\end{array}$

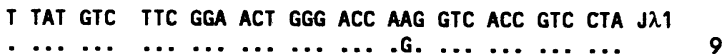

T TAT GTC TTC GGA ACT GGG ACC AAG GTC ACC GTC CTA J JI

$\begin{array}{lllllllllllll}. . & \ldots & \ldots & \ldots & \ldots & \ldots & \ldots & \ldots & \ldots & \ldots & \ldots & \ldots & \ldots\end{array}$

T TAT GTC TTC GGA ACT GGG ACC AAG GTC ACC GTC CTA J J 1

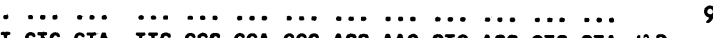

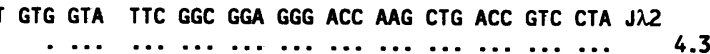

I TGG GTG ITC GGC GGA GGG ACC AAG CTG ACC GTC CTA J 23

$\begin{array}{llllllllllllll} & \ldots & \ldots & \ldots & \ldots & \ldots & \ldots & \ldots & \ldots & \ldots & \ldots & \ldots & \ldots & \ldots\end{array}$

$\begin{array}{llllllllllll}96 & 97 & 98 & 99 & 100 & 101 & 102 & 103 & 104 & 105 & 106 & 107\end{array}$

T TAT GTC TTC GGA ACT GGG ACC AAG GTC ACC GTC CTA J J 1

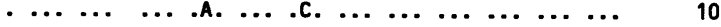

T TGG GTG TTC GGC GGA GGG ACC AAG CTG ACC GTC CTA J J 33

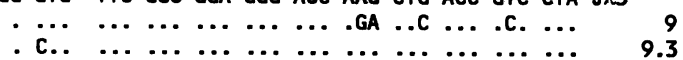

Fig. 3. (Continued)

ously been reported to be identical in nucleotide sequence $(30,50,53)$. In this study, a total of 158 clones contained identifiable $\mathrm{J} \lambda$ gene segments (Table 1C, Fig. 4). Surprisingly, a variant $\mathrm{J} \lambda 3$ gene segment (21), (Genbank Accession Number D87023) was found in 41 cDNA clones $(26 \%)$ and was expressed in all five individuals in this study. The definitive 
Table 1B. Germline derivation of unrearranged $V \lambda$ gene segments amplified from genomic DNA of rheumatoid arthritis patient BC and normal control LB

\begin{tabular}{|c|c|c|c|c|c|c|c|c|}
\hline & V $\lambda$ Family & V2IIIa & \multicolumn{3}{|c|}{ VגIIIb } & \multicolumn{2}{|c|}{ VAIIIc } & \\
\hline PBL & Gene Segment & $3 i$ & 150 & $3 a$ & $3 p$ & III. 1 & $3 e$ & Total \\
\hline RA & BC & 3 & 3 & 0 & 3 & 6 & 1 & 16 \\
\hline Normal & LB & 1 & 2 & 1 & 3 & 8 & 2 & 17 \\
\hline & Total & 4 & 5 & 1 & 6 & 14 & 3 & 33 \\
\hline
\end{tabular}

All but two genomic sequences in Table 1B were 100\% identical to reported sequences of corresponding germline gene segments (Genbank Accession numbers: LBLG9-AF063764; LBLG14; AF063763). Mismatches in number of clones analyzed in Tables 1A and $1 \mathrm{~B}$ are attributable to truncated sequences.

evidence of expression of what is presumed to be an allelic variation of the $J \lambda 3$ gene segment supports our contention that shared changes in $\mathrm{V} \lambda$ gene segments represent novel allelic variants.

Because the downstream PCR primer used for cDNA amplification was derived from a conserved region of the constant region, $\mathrm{J} \lambda$ gene segment utilization in different samples could be compared without concern for bias because of preferential $\mathrm{J} \lambda$ amplification. The pattern of $J \lambda$ expression was similar in the

Table 1C. Germline derivation of $\mathrm{J} \lambda$ gene segments in cDNA clones

\begin{tabular}{|l|c|c|c|c|c|c|c|c|}
\cline { 2 - 9 } \multicolumn{1}{c|}{} & \multicolumn{3}{c|}{ Rheumatoid Arthritis } & \multicolumn{3}{c|}{ Normal } & Total \\
\hline Gene Segment & AS Synovium & AS PBL & BC Synovium & BC PBL & LB PBL & IT PBL & LK PBL & Tol \\
\hline J $\lambda 1$ & $6(20.0 \%)$ & $9(40.9 \%)$ & $6(28.6 \%)$ & $13(65.0 \%)$ & $6(33.3 \%)$ & $12(42.8 \%)$ & $7(36.8 \%)$ & $59(37.3 \%)$ \\
$\mathrm{J} \lambda 2$ & $11(36.7 \%)$ & $9(40.9 \%)$ & $13(61.9 \%)$ & $4(20.0 \%)$ & $7(38.9 \%)$ & $8(28.6 \%)$ & $6(31.6 \%)$ & $58(36.7 \%)$ \\
$\mathrm{J} \lambda 3$ & $13(43.3 \%)$ & $4(18.2 \%)$ & $2(9.5 \%)$ & $3(15.0 \%)$ & $5(27.7 \%)$ & $8(28.6 \%)$ & $6(31.6 \%)$ & $41(26.0 \%)$ \\
\hline Total & 30 & 22 & 21 & 20 & 18 & 28 & 19 & 158 \\
\hline
\end{tabular}

Table 2. Possible variants of known germline V $\lambda$ gene segments expressed in cDNA clones from patients with rheumatoid arthritis and normal controls

\begin{tabular}{|c|c|c|c|c|c|c|}
\hline \begin{tabular}{|l|} 
Gene \\
Segment
\end{tabular} & Codon & Domain & \begin{tabular}{|l|} 
Reported \\
Sequence \\
\end{tabular} & \begin{tabular}{|c|} 
Variant \\
Sequence \\
\end{tabular} & Non-clonally Related Sequences Containing Described Variation & $\begin{array}{l}\% \text { of clones with } \\
\text { variant sequence }\end{array}$ \\
\hline IGLV3S2 & 92 & CDR3 & GAC & GAT & $\frac{\text { ASSynL182,232; }}{21,22,24}$ ASPBLL1, 220,234; BCPBLL11; BCSynL4 & $83.3 \%$ \\
\hline hsig11150 & 32 & CDR1 & TAT & TTT & ASSynL 202, 209; ASPBLL42, 53; BCSynL47; ITPBLL70 & $14.3 \%$ \\
\hline hsig11150 & 33 & CDR1 & GCT & GTT & $\begin{array}{l}\text { ASSynL216; ASPBLL42, 53; BCSynL51; LBPBLL3F; } \\
\text { LKPBLL9; ITPBLL11, 70 }\end{array}$ & $17.8 \%$ \\
\hline hsigl1150 & 46 & FR2 & CTG & TTG & $\begin{array}{l}\text { ASSynL204, 215, 216; ASPBLL48, 51, 59; } \frac{\text { BCSynL47; }}{\text { BCPBLL27; LBPBLL2, 3F, 5; LKPBLL9, 59; ITPBLL13, 45, 70, }} \\
80\end{array}$ & $40.0 \%$ \\
\hline hsig11150 & 52 & CDR2 & AGT & ACT & $\begin{array}{l}\text { ASSynL209, 210, 211, 215, 216; } \\
\text { LKPBLL59, 76, 72; ITPBLL70, } 76\end{array}$ & $28.9 \%$ \\
\hline hsig11150 & 87 & FR3 & TAC & TAT & $\begin{array}{l}\text { ASSynL 84, 202, 209,211, 214, 216; } \\
\text { 51: BCPBLL27; LBPBLL3J, 3K, 3S, 5; ITPBLL45 }\end{array}$ & $35.6 \%$ \\
\hline IIII.1 & 20 & FR1 & AGC & $\mathrm{ACC}$ & ASPBLL2, 12, 13; BCPBLL8; LBPBLL4H; LKPBLL25 & $18.8 \%$ \\
\hline III.1 & 52 & CDR2 & AGC & AAC & 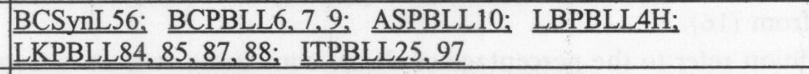 & $39.4 \%$ \\
\hline III.1 & 87 & FR3 & TAC & TAT & ASSynL226; ASPBLL2; BCSynL56; BCPBLL6, 8; ITPBLL25 & $17.7 \%$ \\
\hline IIII.1 & 94 & CDR3 & AGC & AAC & $\begin{array}{l}\text { ASSynL227: } \\
\text { AKPBBLLLL10; } \text { ITPBLL26 }\end{array}$ & $20.5 \%$ \\
\hline $6 \mathrm{~S} 1$ & 43 & FR2 & TCC & GCC & BCSynL1, 3, 38, 59; BCPBLL16: LBPBLL2S, 4; ITPBLL75 & $88.9 \%$ \\
\hline
\end{tabular}




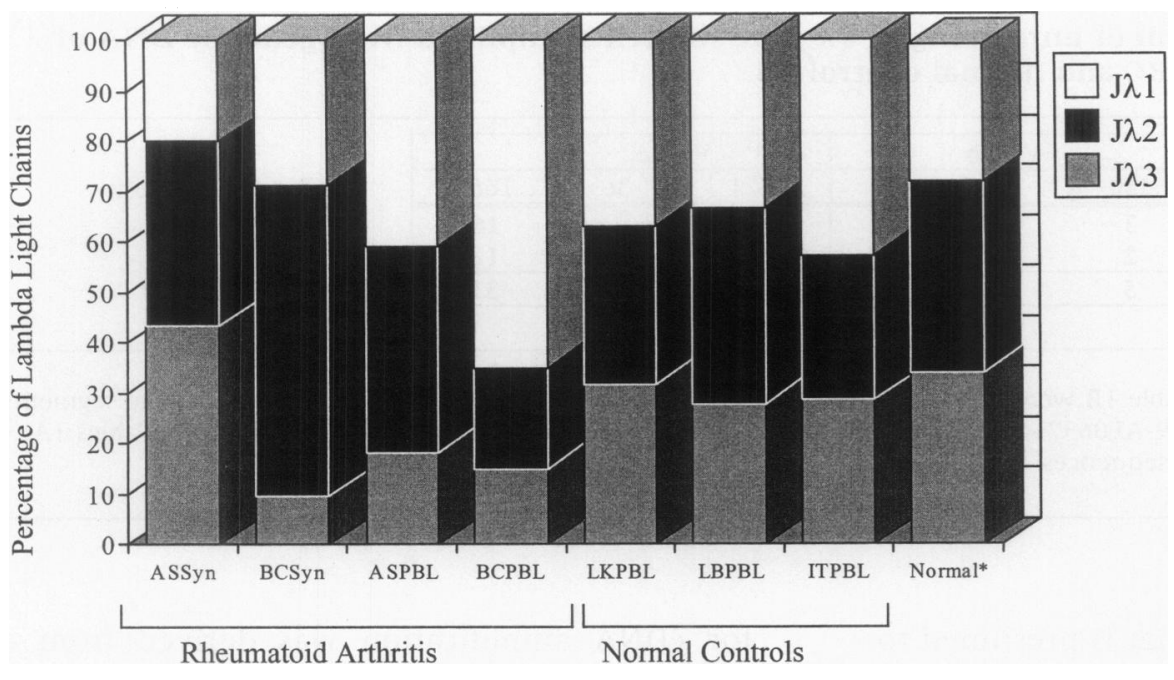

Fig. 4. J $\lambda$ gene segment utilization in RA synovia, RA PBL, and normal PBL. *, Utilization in lambda light chains from normal PBL (47). three normal PBL samples $(\mathrm{J} \lambda 1 \mathrm{3} 3-43 \%, \mathrm{~J} \lambda 2$ $29-39 \%, \mathrm{~J} \lambda 328-32 \%$, Table $1 \mathrm{C}$ ) and closely paralleled that seen in cDNA libraries from PBL of normal individuals (47) (Fig. 4). In RA tissues, however, there was more variability in $\mathrm{J} \lambda$ gene segment utilization. For example, in synovium of patient AS, there was a slightly decreased representation of $J \lambda 1$ and an increased proportion of $J \lambda 3$, whereas AS PBL contained more $\mathrm{J} \lambda \mathrm{l}-$ and $\mathrm{J} \lambda 2$-containing clones and fewer $\mathrm{J} \lambda 3$-containing clones. Clones from BC synovium exhibited a marked increase in $\mathrm{J} \lambda 2$ and a concomitant decrease in
$\mathrm{J} \lambda 3$, whereas BC PBL showed a marked increase in $\mathrm{J} \lambda \mathrm{l}$.

\section{Comparison of $N$-region Addition in $V \lambda$ and $V \kappa$ Transcripts from the Same Tissue Samples}

The percentage of clones containing $P$ nucleotides and $\mathrm{N}$-region addition and the mean number of nucleotides added (among clones that contain $\mathrm{N}$ region addition) are shown in Table 3. Lambda light chain data are shown in comparison to a similar analysis of predominantly $\mathrm{V} \kappa \mathrm{III}$ transcripts from the same tissue samples [(16), Fig. 5]. P nu-

Table 3. $\mathbf{N}$ region and CDR3 lengths of immunoglobulin $\mathrm{V} \lambda$ and $V \kappa$ clones from RA synovia and PBL and normal PBL

\begin{tabular}{|l|c|c|c|c|c|c|c|c|c|c|}
\hline \multirow{4}{*}{$\begin{array}{l}\text { Tissue } \\
\text { Sample }\end{array}$} & $\begin{array}{c}\text { No. Clones } \\
\text { Analyzed }\end{array}$ & $\begin{array}{c}\mathrm{P} \\
\text { Addition }\end{array}$ & $\begin{array}{c}\mathrm{N} \\
\text { Addition }\end{array}$ & $\begin{array}{c}\text { Mean } \\
\text { No. N's* }\end{array}$ & $\begin{array}{c}\text { Mean CDR3 } \\
\text { Length }\end{array}$ & $\begin{array}{c}\text { No. Clones } \\
\text { Analyzed }\end{array}$ & $\begin{array}{c}\text { P } \\
\text { Addition }\end{array}$ & $\begin{array}{c}\text { N } \\
\text { Addition }\end{array}$ & $\begin{array}{c}\text { Mean } \\
\text { No. N's }\end{array}$ & $\begin{array}{c}\text { Mean CDR3 } \\
\text { Length }\end{array}$ \\
\hline AS Syn & 30 & $13.3 \%$ & $50.0 \%$ & $3.3 \pm 6.1$ & $10.5 \pm 1.4$ & 11 & $27.2 . \%$ & $54.5 \%$ & $1.7 \pm 1.2$ & $9.8 \pm 1.0$ \\
\hline AS PBL & 20 & $30.0 \%$ & $45.0 \%$ & $2.4 \pm 1.1$ & $10.7 \pm 1.3$ & 10 & $20.0 \%$ & $60.0 \%$ & $1.7 \pm 1.2$ & $9.9 \pm 0.9$ \\
\hline BC Syn & 21 & $33.3 \%$ & $42.8 \%$ & $1.9 \pm 1.1$ & $10.5 \pm 1.1$ & 14 & $35.7 \%$ & $57.1 \%$ & $1.8 \pm 1.0$ & $9.5 \pm 1.2$ \\
\hline BC PBL & 20 & $10.0 \%$ & $40.0 \%$ & $3.0 \pm 1.3$ & $10.3 \pm 1.0$ & 15 & $33.3 \%$ & $60.0 \%$ & $1.9 \pm 2.3$ & $9.3 \pm 1.0$ \\
\hline LB PBL & 18 & $16.7 \%$ & $33.3 \%$ & $2.5 \pm 1.4$ & $9.9 \pm 1.1$ & 12 & $25.0 \%$ & $16.7 \%$ & $3.0 \pm 2.8$ & $9.1 \pm 0.5$ \\
\hline LK PBL & 19 & $15.8 \%$ & $26.3 \%$ & $2.6 \pm 1.3$ & $9.7 \pm 1.6$ & 11 & $18.1 \%$ & $45.5 \%$ & $3.8 \pm 4.1$ & $9.5 \pm 0.7$ \\
\hline IT PBL & 28 & $32.1 \%$ & $42.9 \%$ & $2.2 \pm 1.6$ & $10.4 \pm 1.1$ & 11 & $18.1 \%$ & $18.1 \%$ & $2.0 \pm 1.4$ & $9.0 \pm 0.6$ \\
\hline
\end{tabular}

V $\kappa$ data are derived from (16).

$\mathrm{P}$ addition and $\mathrm{N}$ addition refer to the percentage of clones containing at least one palindromic nucleotide or nucleotide of $\mathrm{N}$ region addition, respectively. Mean number of nucleotides and CDR3 lengths (expressed as number of amino acid codons) are shown \pm one standard deviation.

* The mean number of nucleotides refers to the average number of nucleotides added among the clones that contain $\mathrm{N}$-region addition. 


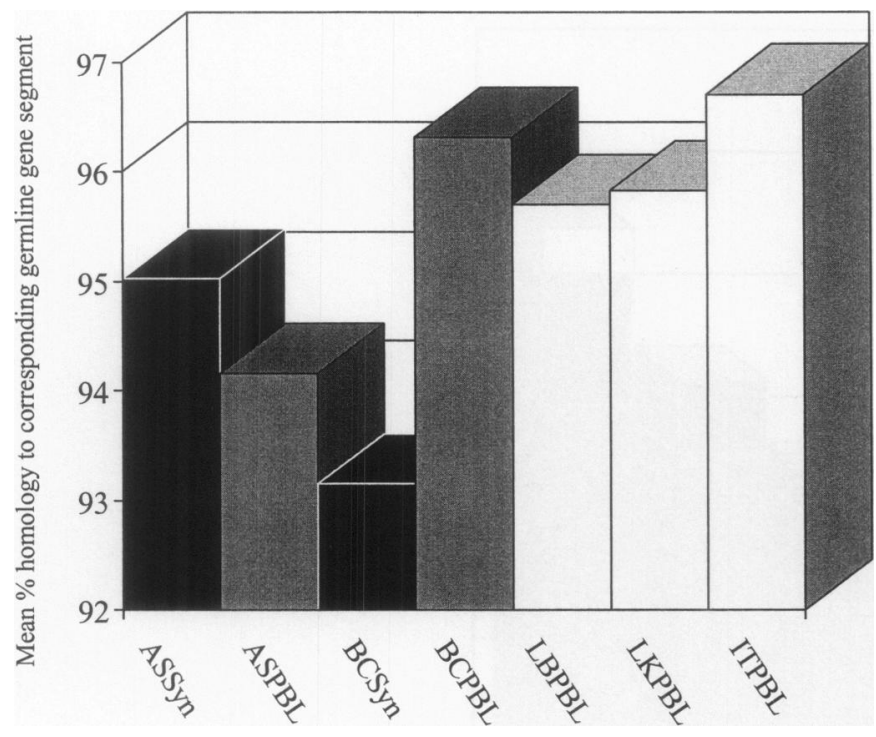

cleotides were present in $10-33 \%$ of $\mathrm{V} \lambda$ transcripts and $18-36 \%$ of $V \kappa$ transcripts. There was no difference between proportions of $\mathrm{V} \lambda$ clones with $\mathrm{P}$ nucleotides among RA tissues (10-33\% of clones) and clones from normal PBL (16-32\%). N-region addition in $\mathrm{V} \lambda$ clones was surprisingly common in normal PBL (range 26-43\%) but was more prevalent among clones from RA synovia (43-50\%) and RA PBL (40-45\%) (Fig. 6).

In all RA samples, there was more $\mathrm{N}$ addition in $V \kappa$ transcripts than in $V \lambda$ transcripts. Surprisingly, in two of the three normal individuals studied, $\mathrm{N}$ regions were more common among $V \lambda$ transcripts than in $V \kappa$ transcripts. Among clones with $\mathrm{N}$-region addition the average num-
Fig. 5. Mean percent homology of expressed $V \lambda$ gene segments to corresponding germline gene segments. This analysis includes only clones that were mutated; clones with $V \lambda$ genes identical to germline were excluded. In general, clones from RA synovia (black bars) and RA PBL (gray bars) were more highly mutated (lower homology) than clones from normal PBL.

ber of nucleotides added ranged from 1.9 to 3.3 (Table 3). One of the AS synovial clones (ASSynL25) contained 25 nucleotides of junctional sequence, which may represent $\mathrm{N}$-region addition or insertion of nucleotides through another mechanism (see Discussion). In both RA patients there was more $\mathrm{N}$-region addition in $\mathrm{V} \lambda$ transcripts from synovia than in those from PBL.

\section{CDR3 Lengths of Lambda Light Chains from RA Synovia, RA PBL, and Normal PBL}

CDR3 intervals were generally longer in $\mathrm{V} \lambda$ transcripts (range 8-16 codons) than in $V \kappa$ transcripts from the same tissue samples (range

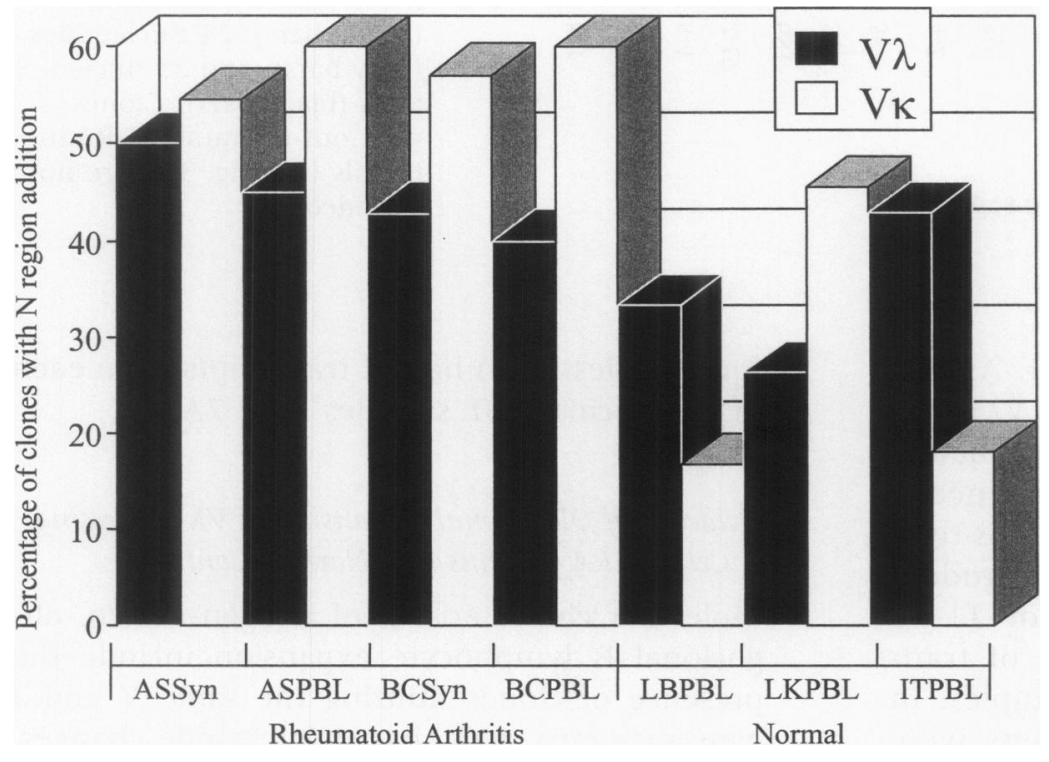

Fig. 6. $\mathrm{N}$-region addition in $\mathbf{V} \boldsymbol{\lambda}-\mathrm{J} \boldsymbol{\lambda}$ joins (black bars) and $\mathrm{V} \kappa-\mathrm{J} \kappa$ joins (white bars) from RA synovia, RA PBL, and normal PBL. VK clones are from ref. 16 and derive primarily from members of the VkIII family. Percentages of $V \kappa$ clones containing $\mathrm{N}$-region addition vary slightly from ref. 16 because of reanalysis to identify $\mathrm{P}$ nucleotides. 


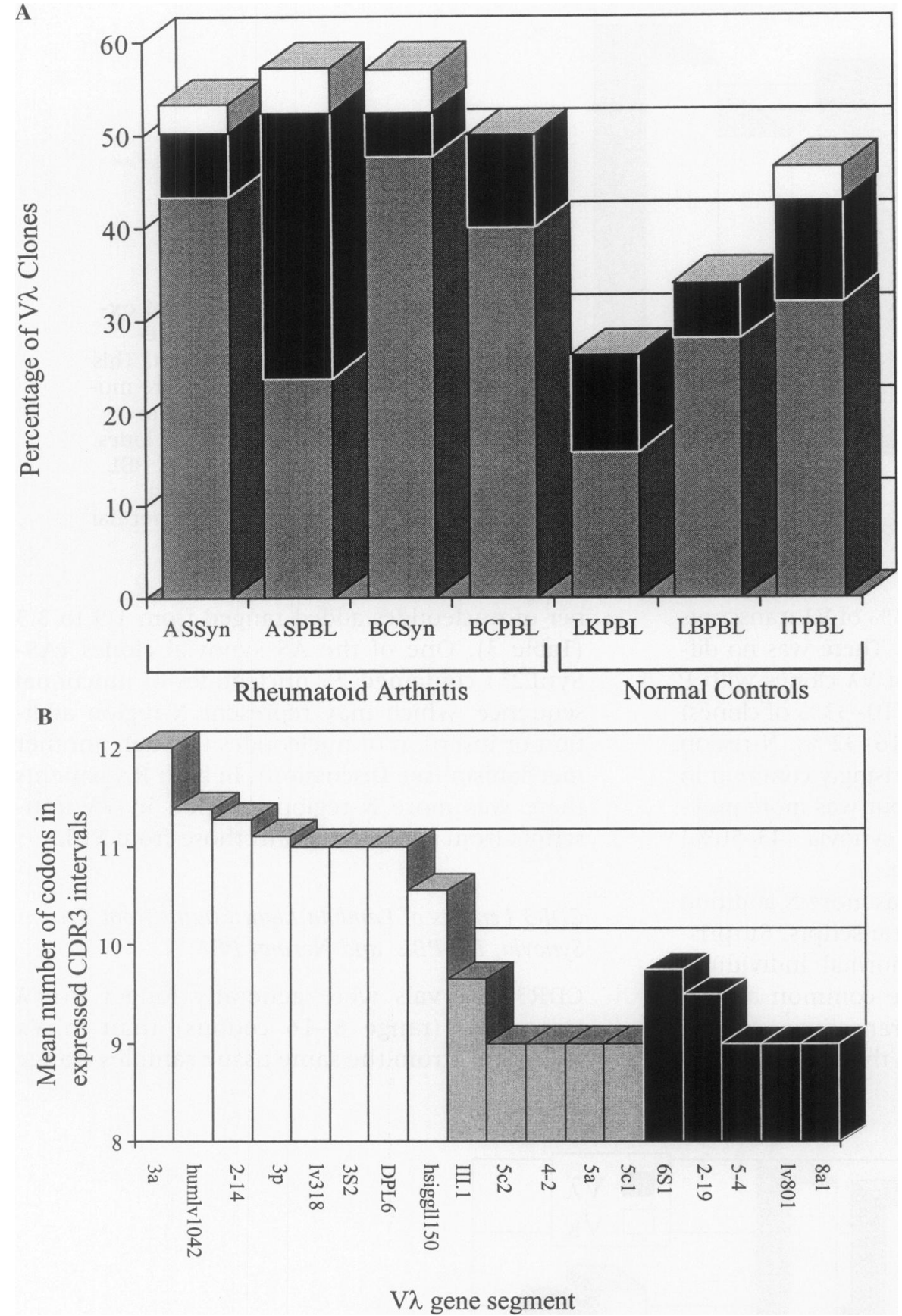

Fig. 7. (A) CDR3 lengths of $V \lambda$ clones from $R A$ synovia, RA PBL, and normal PBL. The proportions of clones with CDR3 intervals of 11 codons (gray segments), 12 codons (black segments) and $>12$ codons (white bars) are shown. Proportions of clones with $<10$ codons are not represented. (B) Mean CDR3 lengths of clones according to the length of the germline component of the $\mathrm{V} \lambda$ gene segment utilized. Germline gene segments are grouped into those with 29 nucleotides (white bars), 24 nucleotides (gray bars), and 23 nucleotides (black bars). Clones with out-of-frame CDR3 intervals (see Fig. 3) were not included.
7-1 1 codons) [(16), Table 3, Fig. 7A]. As was the case for kappa light chains (16), $V \lambda$ transcripts from RA synovium and PBL had a higher mean CDR3 length and contained a higher proportion of long CDR3 intervals than did those from normal PBL ( $p=0.02$, Student $t$-test, two-tailed). CDR3 intervals of 11 or more codons were found in $\geq 50 \%$ of transcripts from each of the four RA samples. In contrast, $\mathrm{CDR} 3$ lengths of $\geq 11$ codons were found in less than half of transcripts from each of the normal PBL samples (Fig. 7A).

\section{Evidence of Oligoclonal Expansion of $V \lambda$-expressing $B$ Cells in RA Patients and Normal Controls}

Molecular characteristics of antigen-driven, oligoclonal B lymphocyte expansion include the presence of clones utilizing the same $\mathrm{V}$ and $\mathrm{J}$ gene segments with shared nucleotide changes, 
similar N-region addition, and identical CDR3 lengths. Several sets of sequences that may represent the products of oligoclonal B-cell expansion were found among clones from RA patient AS synovium and PBL. Clones ASSynL182 and 189 are very mutated $(92.3 \%$ and $92.3 \%$ homology to germline IGLV3S2) and have multiple shared differences (Fig. 8A). Both clones use the $\mathrm{J} \lambda 2$ gene segment and have the same CDR3 length.

The V $\lambda$ gene segments from clones ASSynL211, 209, and 184 are derived from hsigll $150(96.6 \%, 91.6 \%$, and $89.7 \%$ homology, respectively) (Fig. 8B). These three clones have identical $\mathrm{V} \lambda$-J $\lambda$ joins and CDR 3 lengths. Importantly, clones ASSynL211 and 209 have a shared somatic mutation at codon 104 in the $J \lambda 3$ gene segment. Because all the germline $J \lambda$ gene segments are presumably known, this shared mutation is strong evidence of clonal relatedness. ASPBLL48 and 51 are also likely to be clonally related (Fig. $8 \mathrm{C}$ ). They are heavily mutated in the $\mathrm{V} \lambda$ gene segment $(90.8 \%$ and $91.2 \%$ homology to hsiggll150, respectively), have identical $\mathrm{V} \lambda-\mathrm{J} \lambda$ joins, and use the same heavily mutated $J \lambda l$ gene segment. There are five nucleotide differences between ASPBLL48 and ASPBLL51, three of which lead to amino acid replacement. Patient $\mathrm{BC}$ also had evidence of clonal expansion in synovium and PBL. Clones BCSynL47 and 51 are heavily mutated and have shared differences at codons 28, 30, 77, and 93 (Fig. 8D); BCPBLL2 and 4 have shared changes at codons 50, 95A, and 96 (Fig. 8E). Among the clones from normal PBL, only individual LK demonstrated convincing evidence of clonal expansion. Clones LKPBLL76 and 72 are $96.2 \%$ and $95.0 \%$ homologous to hsiggll150, use the same $J \lambda$ gene segment, and have identical $\mathrm{V} \lambda$-J $\lambda$ joins (Fig. 8F). All but seven differences are shared between the two clones.

Levels of Somatic Hypermutation in RA Synovia and $P B L$ and Normal PBL Transcripts Suggest the Subset of $B$ Cells from Which They Are Derived

$\mathrm{V} \lambda$ gene segments expressed in RA synovia were, on average, slightly more mutated than those from RA PBL, which were in turn more mutated than those from normal controls (Fig. 5). The mean percent homologies to germline nucleotide sequence were RA Syn $94.4 \%$, RA PBL $95.4 \%$, and normal PBL $96.7 \%(p=0.002$, ANOVA). Nine of 67 clones (14.9\%) from normal individuals were unmutated, compared with only 3 of
$94(3.2 \%)$ of clones from RA samples $(p=0.03$, Fisher exact, two-tailed). When unmutated sequences were omitted from the analysis, the differences in amount of somatic mutation were still apparent (RA Syn $94.2 \%$, RA PBL $95.2 \%$, and normal PBL $96.1 \%, p=0.02$, ANOVA).

In this cDNA analysis, quantitative differences in immunoglobulin mRNA expression among B cells at various stages of differentiation probably explain discrepant levels of somatic mutation between RA synovia and RA PBL. Synovial infiltrates from patients with long-standing RA typically contain many plasma cells $(54,55)$, which have been shown to have high immunoglobulin mRNA levels (56). Classswitched and $\operatorname{IgM}^{+} / \mathrm{IgD}^{-}$memory $\mathrm{B}$ cells have also been reported to express higher levels of immunoglobulin mRNA than naive B cells (57). Marked levels of somatic mutation were noted in our previous analyses of the synovial $\operatorname{IgG} \mathrm{V}_{\mathrm{H}}$ repertoire of RA patient BC (mean homology to germline $91 \%$ ) $(58)$ and the synovial $V \kappa$ repertoires of RA patients BC (mean homology $94.9 \%$ ) and AS (mean homology $95.8 \%$ ) (16). Thus, the increased somatic mutation in lambda light chains from RA synovia is likely attributable to the presence of plasma cells, which express high levels of mutated sequences. There were fewer unmutated sequences from RA PBL than from normal PBL. Thus, it seems likely that more RA PBL sequences originated from memory $B$ cells (either class-switched or $\operatorname{IgM}^{+} / \mathrm{IgD}^{-}$memory B cells) than from the essentially unmutated naive $\mathrm{B}$ cell $\left(\mathrm{IgM}^{+} / \mathrm{IgD}^{+}\right)$population. In contrast, more of the normal PBL sequences may have been derived from naive $B$ cells.

\section{Potential PCR Artifacts}

We used sequence comparison software that is capable of comparing individual FR and CDR domains with corresponding domains from multiple germline gene segments. Thus, we were able to identify sequences with crossover events involving two different gene segments. We found only one such crossover artifact. BCSynL32 is a clone that contains a crossover artifact, with the FR1 and CDRl domains from the V $\lambda$ VI gene segment 1v6S1 and FR2, CDR2, FR3, and CDR3 from the $V \lambda I$ gene segment humlv1042 (DPL8) (Fig. 2). This so-called jumping PCR artifact occurs when an incomplete product of one amplification cycle serves as a primer for a related sequence, generating a chimeric molecule (59-61). 


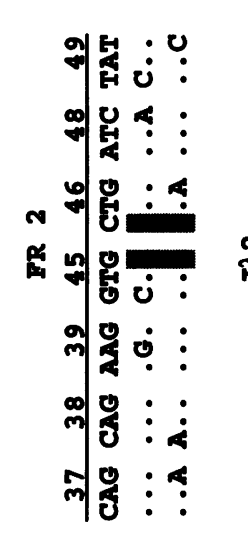

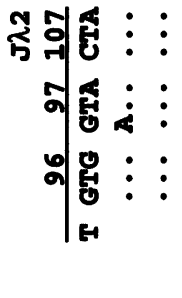

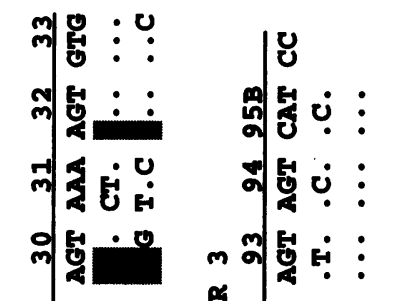

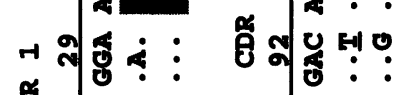

药

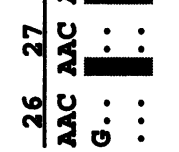

워ํํㅇ:

궁

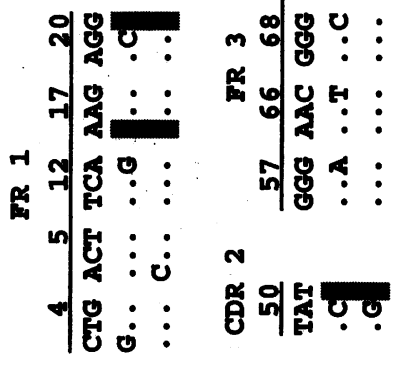

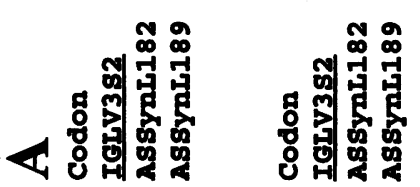
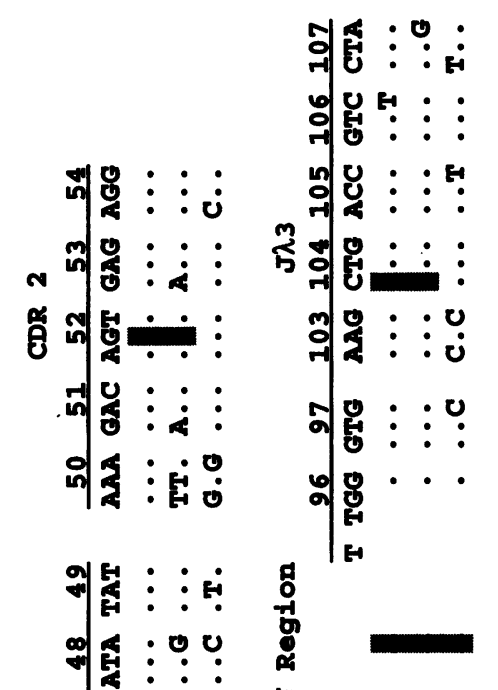

m

N 윙: : :

\%

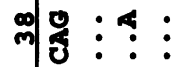

우의 $\mathrm{m}$

읭: :

œ

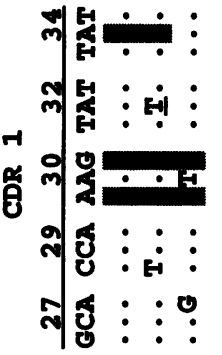

F

이영

ㄱํำ: : :

켄ㄷㅂ : : H.

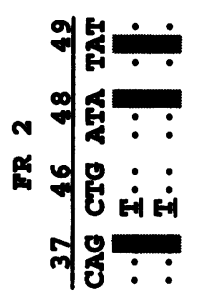

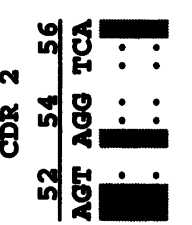

网数:

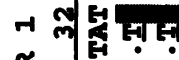

8ิ

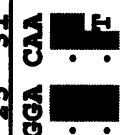

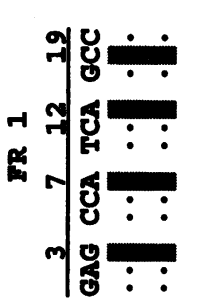

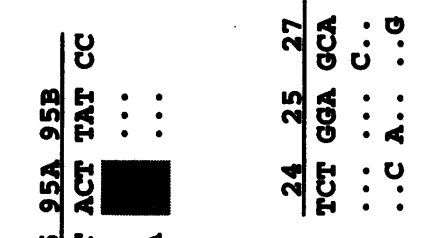

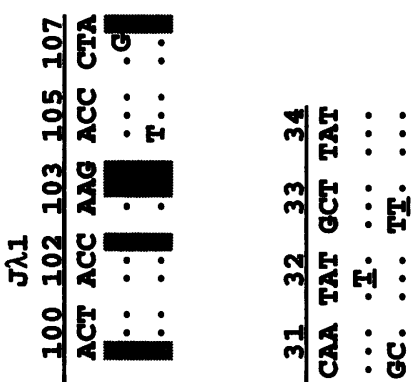

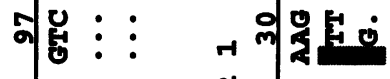

ดัต : : हี่

ஸे

ๆ

ดู

है

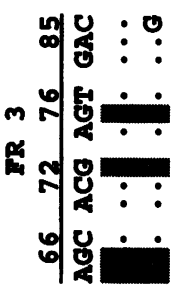

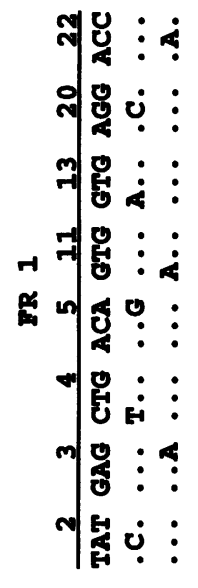

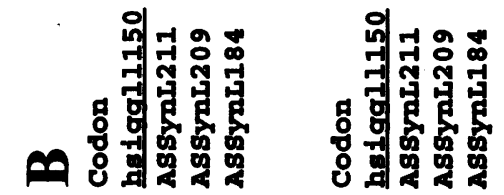
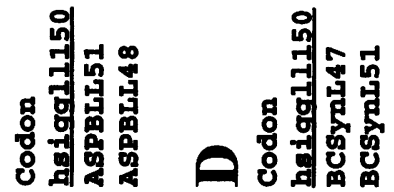
FR 2 $\begin{array}{llllllllll}36 & 37 & 38 & 40 & 41 & 45 & 46 & 47 & 48 & 49\end{array}$ TAC CAG CAG CCA GGC GTG CTG GTG ATA tAT

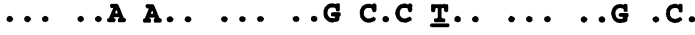

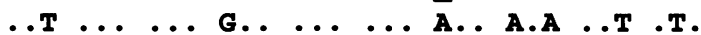

CDR 2

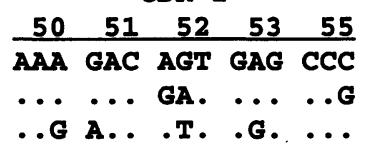

higatig

CSynL47

BCSynL51

hsiggl1150

BCSYnL 47

BCSYnL51

hsiggl1150

BCSYnL47

BCSynL51

$\mathbf{E}$

III. 1

BCPBLL2

BCPBLL4

\section{$\mathbf{F}$}

$\begin{array}{lllllllllllllllllll}59 & 60 & 62 & 64 & 66 & 67 & 69 & 70 & 71 & 72 & 74 & 75 & 76 & 77 & 80 & 81 & 85 & 86 & 87\end{array}$

TCC AGC TCA ACA ACA GTC ACG ACC ATC AGT GGA GCA GAA GAC TAT TAC

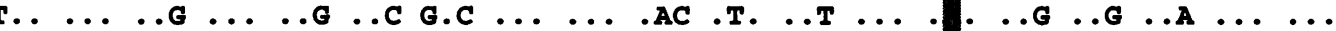

... ..A A.. . .

CDR 3

$\begin{array}{llllllllll}88 & 89 & 90 & 91 & 92 & 93 & 94 & 95 & 95 \mathrm{~A} & 95 \mathrm{~B}\end{array}$

CAA TCA GCA GAC AGC AGT GGT ACT TAT CC

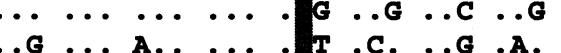

$\mathrm{J \lambda 2}$

$\begin{array}{rrrrrr}96 \quad 97 \quad 98 & 103 & 104 & 107\end{array}$

$\ldots T \ldots T$. . . . .

C.T

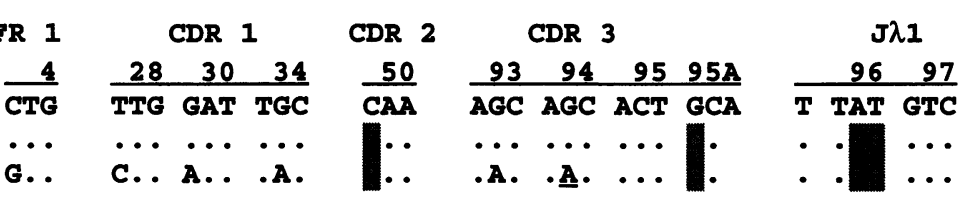

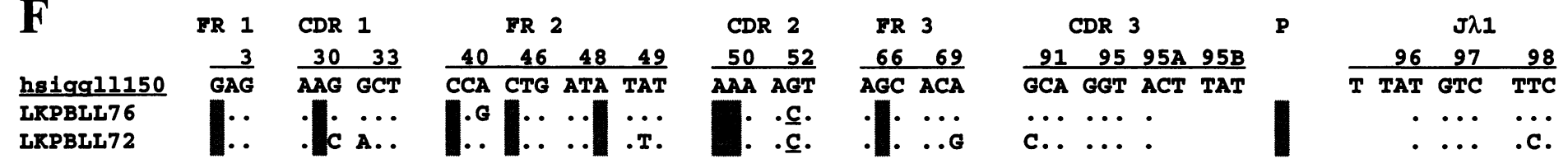

Fig. 8. Nucleotide sequences that may be the result of oligoclonal B-cell expansion, defined as utilizing the same $\mathbf{V}$ and $\mathbf{J}$ gene segments with shared mutations and having identical CDR3 lengths. Only codons for which there are differences from the corresponding germline gene segment are shown. Dots denote nucleotide homology. Shared nucleotide changes are shown as shaded boxes, with changes that may represent possible allelic variations (see Table 2) underlined. Palindromic (P) nucleotides are shown in lower case. (A) IGLV3S2-derived clones from synovium of RA patient AS. (B) hsiggll150derived clones from synovium of RA patient AS. (C) hsiggll150-derived clones from PBL of RA patient AS. (D) hsiggll150-derived clones from synovium of RA patient BC. (E) VAIII.1-derived clones from PBL of RA patient BC. (F) hsiggll150-derived clones from the PBL of normal individual LK. 
Although our sequence analysis software can easily identify a hybrid molecule containing two different germline $\mathrm{V} \lambda$ gene segments, identification of crossovers between two transcripts expressing the same $V \lambda$ gene segment represents a more difficult problem. In all clones thought to be genealogically related (Fig. 8), there were nonshared differences in multiple FR and CDR domains. To explain these findings by jumping PCR artifact, one would have to posit that multiple, closely spaced crossover occurred. This is unlikely from a statistical point of view because of the relatively small number of PCR cycles used for amplification.

Because a nonproofreading DNA polymerase (Taq DNA polymerase) was used in PCR, we were concerned about the possibility of PCR errors. Estimates of the fidelity of Taq DNA polymerase vary from $2.0 \times 10^{-5}$ errors per base pair $(62)$ to $1.1 \times 10^{-4}$ errors per base pair $(63,64) ; 2.4 \times 10^{-5}$ frameshift mutations per base pair are estimated to occur in Taq DNA polymerase PCR reactions (63). The sequence analysis of unrearranged $\mathrm{V} \lambda$ gene segments from $\mathrm{T}$ lymphocytes, in which somatic hypermutation of immunoglobulin genes does not occur, allowed us to estimate the Taq error rate. From a total of 9472 base pairs that were sequenced, five single base pair substitutions (and no frameshift mutations) were found. If one assumes that all five of these nucleotide changes were due to Taq error, the maximum error rate is $5.3 \times 10^{-4}$ error changes per base pair. Thus, in the reported cDNA sequences, the error rate is presumably very low (approximately one base pair error in every third sequence).

\section{Discussion}

$N$-region Addition during Immunoglobulin Lambda Light Chain Gene Rearrangement

The finding of $N$-region addition in $V \lambda-J \lambda$ joins from RA patients and normal individuals has important implications regarding the generation of CDR3 diversity during immunoglobulin gene rearrangement in normal B cells. In human bone marrow, stem cells progress through the pro- $\mathrm{B}$-cell, pre-B-cell, and immature B-cell stages of differentiation before becoming mature B cells (reviewed in ref. 65). In the pro-B-cell stage, the immunoglobulin heavy chain locus undergoes rearrangement and the enzyme responsible for $\mathrm{N}$-region addi- tion, TdT, is present in the nucleus of the cell. In the pre-B-cell stage, kappa light chains undergo rearrangement. Although TdT protein has not been shown to be present at the time of kappa light chain rearrangement, $\mathrm{N}$-region addition is clearly present in kappa light chains from normal individuals and those with RA (15-18).

The current theory for immunoglobulin light chain rearrangement holds that if successful kappa rearrangement fails on both alleles, then lambda light chain rearrangement occurs. Thus, lambda light chain rearrangement is thought to occur well after the expression of TdT. Our analysis of $\mathrm{V} \lambda-\mathrm{J} \lambda$ joins, however, provides clear evidence of $\mathrm{N}$-region addition, presumably due to TdT activity at the time of lambda light chain rearrangement. Surprisingly, in two of the three normal individuals studied, there was $\mathrm{N}$-region addition in a higher proportion of $\mathrm{V} \lambda$ transcripts than $V \kappa$ transcripts. Thus, our data provide support for the hypothesis that TdT is present throughout all stages of immunoglobulin gene rearrangements in B cells from normal individuals. We also found more $\mathrm{N}$-region addition in lambda light chains from patients with RA than in those from normal individuals. The same is true of the kappa repertoire of RA patients (Fig. 6) (16), which suggests that TdT may be abnormally regulated in RA.

There are several potential explanations for the presence of non-germline-encoded nucleotides at the V-J junctions of lambda light chains. One possibility is that lambda light chain rearrangement occurs earlier than was previously thought, such as before heavy chain rearrangement or after heavy chain rearrangement but before kappa light chain rearrangement. Kubagawa et al. documented pro-B-cell lines that had undergone kappa rearrangements at one or both alleles but contained heavy chain loci without $\mathrm{V}_{\mathrm{H}}-\mathrm{D}_{\mathrm{H}}-\mathrm{J}_{\mathrm{H}}$ rearrangements (66). Some of the kappa light chain rearrangements in these kappa-only cell lines do contain $\mathrm{N}$ regions (67).

An alternative explanation for $\mathrm{N}$-region addition in $\lambda$ chains is that the current theory of rearrangement order (heavy chain, then kappa light chain, then lambda light chain) is correct, but that TdT is expressed in B cells through the mature B cells stage. Support for this finding lies in the description of a small subpopulation of pre-B cells expressing both nuclear TdT and cytoplasmic $\mu$ heavy chains (68). 
Allelic Variations in the Human Immunoglobulin Lambda Locus

In addition to providing another mechanism for antibody diversity, the presence of allelic variants in the human lambda locus has important implications regarding the analyses of somatic hypermutation and assessment of clonality. The amounts of somatic hypermutation in this study were calculated with the assumption that clones were derived from known $\mathrm{V} \lambda$ gene segments. Each expressed $V \lambda$ gene segment was assigned a presumed progenitor gene segment based on highest degree of homology. Although the human $\mathrm{V} \lambda$ locus has been sequenced by two groups of investigators $(20,21)$, there may be unreported variants of $\mathrm{V} \lambda$ gene segments. The levels of somatic mutation and the degree of oligoclonality reported here may be overestimated if there are $\mathrm{V} \lambda$ gene segments or additional unreported allelic variations of previously described germline gene segments.

Kawasaki et al. assessed the degree of allelic variation of the human immunoglobulin lambda locus by comparing nucleotide differences between their sequence and two cosmid clones from different sources (one from a Caucasian individual and another from a Japanese individual) (21). They found 100 nucleotides over a span of 39,236 nucleotides that were thought to represent allelic variations. Although the number of differences located within coding regions was not reported, there appear to be relatively frequent single nucleotide variations in the human immunoglobulin lambda locus. Thus, additional novel allelic variants are likely to be found in future studies of lambda light chain expression.

Nucleotide Insertions and Deletions in VX Gene Segments May Occur during Somatic Hypermutation in a Germinal Center (GC) Reaction

Single or multiple nucleotide insertions and deletions have been observed in heavy chain variable $\left(\mathrm{V}_{\mathrm{H}}\right)$ domains from germinal center (GC) B cells. Using a single-cell PCR approach, Goossens et al. sequenced rearranged $V_{H}$ domains from naive and GC B cells (69). No deletions or insertions were found in naive $B$ cells, but $\sim 4 \%$ of in-frame and $>40 \%$ of outof-frame (OOF) rearrangements of GC B cells had deletions and/or insertions of variable length. Wilson et al. also noted insertions and deletions in somatically mutated $\mathrm{V}_{\mathrm{H}}$ gene segments from $\mathrm{CD}_{3} 8^{+} / \mathrm{IgD}^{-}$GC $\mathrm{B}$ cells and
$\mathrm{CD}^{-} 8^{-} / \mathrm{IgD}^{-}$memory $\mathrm{B}$ cells from human tonsil (70). Eight of nine insertions/deletions were present in the CDR1 or CDR2 domains. In our previous analysis of $18 \mathrm{immunoglobu-}$ lin $V_{H}$ gene segments from RA synovium, we found one highly mutated $V_{H} 4$-containing transcript with a two-codon insertion in CDRl (71).

In the present study, we found two lambda light chain clones with insertions or deletions that may be the result of somatic hypermutation in the GC reaction. ASSynL191 has a onecodon deletion in CDRl and LKPBLL68 contains a one-codon insertion in CDRl (Fig. 2). Both clones are somatically mutated: ASSynL 191 is $95.2 \%$ homologous to its progenitor germline gene segment, while LKPBLL68 shares $92.3 \%$ homology to its germline gene segment. Several clones in the present study were found to have single base pair insertions or deletions that may reflect somatic mutation (69) or alternatively, frameshift artifacts induced by Taq DNA polymerase. Our data suggest that insertions and deletions occur as a result of somatic hypermutation not only in heavy chains but in lambda light chains as well.

CDR3 Intervals of Lambda Light Chains Are Longer than Those of Kappa Light Chains and the Lengths Are Heavily Influenced by $V \lambda$ Gene Segment Utilization

In both RA patients and normal individuals, lambda CDR3 intervals were longer, on average, than CDR3 intervals from the kappa light chains of the same tissue samples. In immunoglobulin light chain rearrangements, the number of nucleotides at the $V_{L}-J_{L}$ join and thus the CDR3 length are dependent upon the amount of exonuclease activity at the $\mathrm{V}$ and $\mathrm{J}$ termini of the join and the number of $\mathrm{N}$ nucleotides inserted by TdT. Germline $\mathrm{J} \kappa$ and $\mathrm{J} \lambda$ gene segments typically contain 7 nucleotides in the region that encodes the CDR3 (16). Vk gene segments have CDR3 components that are remarkably constant in length (23 nucleotides). In contrast to $V \kappa$ gene segments, there is considerable variation in the number of nucleotides in the CDR 3 components of germline V $\lambda$ gene segments. Gene segments IGLV3S2, 2-14, humlv318, hsiggll150, 3p, 3a, humlv1042, and DPL6 contain 29 nucleotides in the germline CDR3 component. Gene segments III.1, 4-2, hsiglv5a, hsiglv $5 \mathrm{cl}$, and hsiglv $5 \mathrm{c} 2$ have $24 \mathrm{nu}-$ 
cleotides in the CDR3 component, while gene segments $2-19,8 \mathrm{Al}, \mathrm{lv} 801,6 \mathrm{sl}$, and 4 a have 23 nucleotides.

In the present study, the 96 clones containing $\mathrm{V} \lambda$ gene segments with 29 nucleotides in the germline CDR3 component had a mean CDR3 length of 10.9 codons, the 41 clones containing $\mathrm{V} \lambda$ gene segments with germline CDR3 component of 24 nucleotides had a mean CDR3 length of 9.5 codons, and the 16 clones with $\mathrm{V} \lambda$ gene segments containing 23 nucleotides had a mean CDR3 length of 9.4 codons $(p<0.0001$, ANOVA) (Fig. 7B). Thus, in contrast to the situation in the kappa repertoire, the germline $V \lambda$ gene segment used in the rearrangement has a strong influence on the length of the expressed cDNA CDR3 interval.

\section{Enrichment for Unusually Long CDR3 Intervals in Both Lambda and Kappa Light Chains in RA Patients}

Compared with normal PBL, RA synovia and PBL had higher proportions of clones with long CDR3 intervals. This difference is explained in part by a higher proportion of $V \lambda$ gene segments with long CDR3 components among the RA clones. Gene segments IGLV3S2, 2-14, humlv318, hsiggll 150, 3p, 3a, humlv1042, and DPL6, which contain 29 nucleotides in the germline CDR3 component were found in $64.8 \%$ of RA clones, versus $57.6 \%$ of normal controls. Another contributing factor to enrichment of longer CDR3 intervals in RA is a higher proportion of clones with $\mathrm{N}$-region addition.

The enrichment of longer CDR3 intervals in both the kappa and lambda light chain repertoires of RA patients suggests either positive antigenic selection of unusual B cells or abnormal immunoglobulin gene rearrangement. These explanations are not mutually exclusive, and both may occur to some degree in RA patients. In the first scenario, lambda light chains expressing unusually long CDR3 intervals are generated in both normal individuals and RA patients. Subsequently, normal individuals show no preferential positive selection of $B$ cells that by chance contain kappa or lambda light chains with unusual CDR 3 intervals. In contrast, RA patients exhibit positive antigenic selection and clonal outgrowth of such B cells, possibly as a result of the chronic inflammatory response. Support for this hypothesis is the finding that alterations in the sequence at $\mathrm{V} \kappa-\mathrm{J} \kappa$ joins can abrogate antigen binding of the antibody (72).

In addition, there is substantial evidence that RA is an antigen-driven disease $(17,24,73-77)$. We have previously reported oligoclonal B-cell expansion in the immunoglobulin heavy chain $(58,78)$ and kappa light chain (27) repertoires of synovial tissue of RA patient $B C$, which suggests an antigen-driven B-cell response. Furthermore, the clonally expanded kappa light chain clone contained an unusually long CDR3 interval (27). In the present study, we found sets of genealogically related sequences in the lambda repertoire of RA patients BC and AS. Oligoclonality of the synovial B-cell population thus appears to be a common feature of RA synovium.

An alternative explanation for the unusual $\mathrm{V} \lambda-\mathrm{J} \lambda$ joins in RA is that there may be differences in the regulation of expression of proteins involved in the rearrangement process, such as RAG-1, RAG-2, and TdT, resulting in abnormal development of the naive B-cell repertoire in bone marrow. Immunoglobulin heavy and light chain gene segments undergo a highly regulated series of $\mathrm{V}(\mathrm{D}) \mathrm{J}$ gene segment rearrangements to generate a functional antibody. $\mathrm{V}(\mathrm{D}) \mathrm{J}$ recombination requires a RSS (composed of a heptamer, 12- or 23-base pair spacer and a nonamer), RAG-1, and RAG-2 (79). Formation of a double-strand break at a RSS occurs during $V(D) J$ recombination, with the cleavage reaction divided into two distinct steps: nicking and hairpin formation. A nick is introduced at the 5 '-end of the signal sequence, followed by breakage of the other DNA strand, resulting in a hairpin structure at the coding end and a blunt signal end (79). A DNA-binding protein complex containing Ku70, Ku80 subunits, RAG-1, RAG-2, and DNA ligase performs $\mathrm{V}(\mathrm{D}) \mathrm{J}$ joining (80).

Clone ASSynL25 is of particular interest with regard to possible dysregulation of immunoglobulin gene segment rearrangement in RA. The $\mathrm{V} \lambda$-J $\lambda$ join of this clone contains 25 nucleotides that do not appear to be encoded by the V $\lambda$ III.1 or $J \lambda 2$ sequence, resulting in a CDR3 interval of 16 amino acid codons (Fig. 3). One possible explanation for this extremely long $\mathrm{V} \lambda-\mathrm{J} \lambda$ join is $\mathrm{N}$-region addition, but a more likely explanation for the presence of this 25 base pair insertion is the presence of an insertion that is duplicated from the V VIII. 1 gene segment. Sixteen of the 25 nucleotides at the $\mathrm{V} \lambda-\mathrm{J} \lambda$ join are identical to the sequence in codons 90 to $95 \mathrm{~A}$ of the germline 
III.l gene segment, shown as underlined nucleotides in Figure 3A. Thus, there is evidence of unusual immunoglobulin rearrangement in RA synovium.

Expression of RAG-1 and RAG-2 and Receptor Editing in B Cells in Normal Secondary Lymphoid Organs: Implications for $R A$ and Other Chronic Inflammatory Diseases

Among the mechanisms of avoiding production of autoreactive sequences are clonal deletion, clonal anergy, and receptor editing. Receptor editing involves changing an autoreactive variable region to a different (presumably nonautoreactive) variable region through a secondary rearrangement (81-83). In order for this to occur, the $V(D) J$ recombination machinery must be maintained or reactivated. RAG-1 and RAG-2 were initially thought to be expressed in $B$ cells only during B-cell development in bone marrow. However, RAG-1 and RAG-2 have recently been found to be expressed in germinal center (GC) B cells of mice, with evidence of secondary rearrangements and receptor editing (84-86).

There is circumstantial evidence suggesting that RA synovia may act as a lymphoid organ. Nodular lymphocytic infiltrates that are histologically similar to normal GC have been found in the subsynovial layer of some patients with RA (87-90), Lyme disease (91), and reactive arthritis (92), and in inflamed liver tissue from patients with chronic hepatitis B and C (93-95). We have documented the presence of clonally related immunoglobulin heavy and kappa light chain sequences in RA synovium, which suggests in situ antigenic selection $(27,58,78)$. Berek and colleagues have reported clonally related sequences from within GC-like structures in RA synovia (77). The histologic similarities between RA synovia and normal lymphoid tissues containing GC, and the recent findings of RAG-1 and RAG-2 expression in a subset of normal GC B cells suggest that RAG-1 and RAG-2 may be expressed in RA synovia. If so, secondary rearrangements may be possible in synovium of patients with long-standing RA.

In summary, these data demonstrate that in humans, $\mathrm{N}$-region addition enhances antibody diversity at all stages of immunoglobulin gene rearrangement. The structural diversity of lambda light chain CDR3 intervals is greater than that of kappa light chains, largely due to variability in the lengths of germline $V \lambda$ gene segments. As in the kappa light chain repertoire, the lambda light chains of RA patients are enriched for sequences with long CDR3 intervals. Finally, the presence of clonally related sequences in RA synovia and PBL supports an antigen-driven B-cell response in RA. We speculate that RAG-1 and RAG-2 expression may occur in a subset of RA synovial B cells, leading to secondary immunoglobulin gene rearrangements, as has recently been reported in normal peripheral lymphoid organs. The presence of GC-like structures capable of generating a B-cell response within RA synovia raises the possibility that local antigens can propagate the chronic inflammatory response.

\section{Acknowledgments}

This work was supported by a VA Merit Review grant and NIH grant AR44243. The technical assistance of Stephanie Byer and Jennifer Collins is greatly appreciated. The author thanks Drs. Ralf Küppers, Peter Burrows, Zhixin Zhang, and Harry W. Schroeder, Jr., for critical review of the manuscript.

This work was published in part in abstract form in Arthritis Rheum. 39(Suppl.): S159, 1996 and Arthritis Rheum. 40(9Suppl.): S246, 1997.

\section{References}

1. Harris ED Jr. (1990) Rheumatoid arthritis: pathophysiology and implications for treatment. N. Engl. J. Med. 322: 1277-1289.

2. Zvaifler NJ. (1973) Immunopathology of joint inflammation in rheumatoid arthritis. Adv. Immunol. 16: 265-336.

3. Arend WP. (1997) The pathophysiology and treatment of rheumatoid arthritis. Arthritis Rheum. 40: 595-597.

4. Mellors RC, Heimer R, Corcos J, Korngold L. (1959) Cellular origin of rheumatoid factor. J. Exp. Med. 110: 875-886.

5. Smiley JD, Sachs C, Ziff M. (1968) In vitro synthesis of immunoglobulin by rheumatoid synovial membrane. J. Clin. Invest. 47: 624-632.

6. Dreyer WJ, Bennett JC. (1965) The molecular basis of antibody formation: a paradox. Proc. Natl. Acad. Sci. U.S.A. 54: 864-869.

7. Sanz I. (1991) Multiple mechanisms participate in the generation of diversity of human $\mathrm{H}$ chain CDR3 regions. J. Immunol. 147: 1720-1729.

8. Tonegawa S. (1983) Somatic generation of antibody diversity. Nature 302: 575-581.

9. Max EE. (1993) Immunoglobulins: molecular genetics. In: Paul WE (ed). Fundamental Immunology, 3rd ed. Raven Press, New York, pp. 315-382. 
10. Kabat EA, Wu TT, Perry HM, Gottesman KS, Foeller C. (1991) Sequences of Proteins of Immunological Interest, 5th ed. NIH Publ \#91-3242. U.S. Department of Health and Human Services, Bethesda, MD.

11. Desiderio SV, Yancopoulos GD, Paskind $M$, et al. (1984) Insertion of $\mathrm{N}$ regions into heavy-chain genes is correlated with expression of terminal deoxytransferase in B cells. Nature 311: 752-755.

12. Klein U, Küppers R, Rajewsky K. (1993) Human $\mathrm{IgM}^{+} \mathrm{IgD}^{+} \mathrm{B}$ cells, the major $\mathrm{B}$ cell subset in the peripheral blood, express $V \kappa$ genes with no or little somatic mutation throughout life. Eur. J. Immunol. 23: 3272-3277.

13. Weber J-C, Blaison G, Martin T, Knapp A-M, Pasquali J-L. (1994) Evidence that the VkIII gene usage is nonstochastic in both adult and newborn peripheral B cells and that peripheral CD5+ adult B cells are oligoclonal. J. Clin. Invest. 93: 20932105.

14. Klein R, Jaenichen R, Zachau HG. (1993) Expressed human immunoglobulin kappa genes and their hypermutation. Eur. J. Immunol. 23: 32483262.

15. Victor KD, Capra JD. (1994) An apparently common mechanism of generating antibody diversity: length variation of the $\mathrm{V}_{\mathrm{L}}-\mathrm{J}_{\mathrm{L}}$ junction. Mol. Immunol. 31: 39-46.

16. Bridges SL Jr, Lee SK, Johnson ML, et al. (1995) Somatic mutation and CDR3 lengths of immunoglobulin $\kappa$ light chains expressed in patients with rheumatoid arthritis and normal individuals. J. Clin. Invest. 96: 831-841.

17. Lee SK, Bridges SL Jr, Koopman WJ, Schroeder HW Jr. (1992) The immunoglobulin kappa light chain repertoire expressed in the synovium of a patient with rheumatoid arthritis. Arthritis Rheum. 35: 905-913.

18. Martin T, Blaison G, Levallois H, Pasquali JL. (1992) Molecular analysis of the VkIII-JK junctional diversity of polyclonal rheumatoid factors during rheumatoid arthritis frequently reveals $\mathbf{N}$ addition. Eur. J. Immunol. 22: 1773-1779.

19. Chuchana P, Blancher A, Brockly F, Alexandre D, Lefranc G, Lefranc M-P. (1990) Definition of the human immunoglobulin variable lambda (IGLV) gene subgroups. Eur. J. Immunol. 20: 1317-1325.

20. Williams SC, Frippiat JP, Tomlinson IM, Ignatovich O, Lefranc MP, Winter G. (1996) Sequence and evolution of the human germline $\mathrm{V}$ lambda repertoire. J. Mol. Biol. 264: 220-232.

21. Kawasaki K, Minoshima S, Nakato E, et al. (1997) One-megabase sequence analysis of the human immunoglobulin lambda gene locus. Genome Res. 7: 250-261.

22. Bridges SL Jr, Lavelle JC, Lee SK, Byer S, Schroeder HW Jr. (1997) CDR3 fingerprinting of immunoglobulin kappa light chains expressed in rheumatoid arthritis: evidence of antigenic selection or dysregulation of gene rearrangement in B cells. Ann. N.Y. Acad. Sci. 815: 423-426.

23. Ermel RW, Kenny TP, Wong A, Solomon A, Chen PP, Robbins DL. (1994) Preferential utilization of a novel $\mathrm{V}$ lambda 3 gene in monoclonal rheumatoid factors derived from the synovial cells of rheumatoid arthritis patients. Arthritis Rheum. 37: 860868.

24. Ermel RW, Kenny TP, Chen PP, Robbins DL. (1993) Molecular analysis of rheumatoid factors derived from rheumatoid synovium suggests an antigen-driven response in inflamed joints. Arthritis Rheum. 36: 380-388.

25. Harindranath $\mathrm{N}$, Goldfarb IS, Ikematsu $\mathrm{H}$, et al. (1991) Complete sequence of the genes encoding the $V_{H}$ and $V_{L}$ regions of low- and high- affinity monoclonal IgM and $\operatorname{Ig} \mathrm{A}_{1}$ rheumatoid factors produced by $\mathrm{CD}^{+} \mathrm{B}$ cells from a rheumatoid arthritis patient. Int. Immunol. 3: 865-875.

26. Fang Q, Kannapell CC, Gaskin F, Solomon A, Koopman WJ, Fu SM. (1994) Human rheumatoid factors with restrictive specificity for rabbit immunoglobulin G: auto- and multi-reactivity, diverse $\mathrm{V}_{\mathbf{H}}$ gene segment usage and preferential usage of VAIIIb. J. Exp. Med. 179: 1445-1456.

27. Lee SK, Bridges SL Jr, Kirkham PM, Koopman WJ, Schroeder HW Jr. (1994) Evidence of antigen receptor-influenced oligoclonal B lymphocyte expansion in the synovium of a patient with longstanding rheumatoid arthritis. J. Clin. Invest. 93: 361-370.

28. Chirgwin JM, Przybyla AE, MacDonald RJ, Rutter WJ. (1979) Isolation of biologically active ribonucleic acid from sources enriched in ribonuclease. Biochemistry 18: 5294.

29. Daley MD, Peng HQ, Misener V, Liu XY, Chen PP, Siminovitch KA. (1992) Molecular analysis of human immunoglobulin V lambda germline genes: subgroups V lambda III and V lambda IV. Mol. Immunol. 29: 1515-1518.

30. Combriato G, Klobeck HG. (1991) V lambda and J lambda-C lambda gene segments of the human immunoglobulin lambda light chain locus are separated by $14 \mathrm{~kb}$ and rearrange by a deletion mechanism. Eur. J. Immunol. 21: 1513-1522.

31. Blomberg BB, Glozak MA, Donohoe ME. (1995) Regulation of human lambda light chain gene expression. Ann. N.Y. Acad. Sci. 764: 84-98.

32. English D, Andersen BR. (1974) Single-step separation of red blood cells, granulocytes and mononuclear leukocytes on discontinuous density gradients of Ficoll-Hypaque. J. Immunol. Methods 5: 249-252.

33. Madsen $M$, Johnsen HE, Hansen PW, Christiansen SE. (1980) Isolation of human T and B lymphocytes by E-rosette gradient centrifugation. Characterization of the isolated subpopulations. J. Immunol. Methods 33: 323-336.

34. Ausubel FM, Brent R, Kingston RE, Moore DD, Seidman JG, Smith JA, et al., eds. (1997) Prepa- 
ration and analysis of DNA. In: Current Protocols in Molecular Biology. John Wiley \& Sons, New York, pp. 2.1.1-2.1.2.

35. Frippiat JP, Lefranc MP. (1994) Genomic organisation of $34 \mathrm{~kb}$ of the human immunoglobulin lambda locus (IGLV): restriction map and sequences of new V lambda III genes. Mol. Immunol. 31: 657-670.

36. Sanger F, Nicklen S, Coulson AR. (1977) DNA sequencing with chain-terminating inhibitors. Proc. Natl. Acad. Sci. U.S.A. 74: 5463-5467.

37. Elgavish RA, Schroeder HW Jr. (1993) SAW: A graphical user interface for the analysis of immunoglobulin variable domain sequences. Biotechniques 15: 1066-1071.

38. Lafaille JJ, DeCloux A, Bonneville M, Takagaki Y, Tonegawa S. (1989) Junctional sequences of $T$ cell receptor gamma delta genes: implications for gamma delta $\mathrm{T}$ cell lineages and for a novel intermediate of V-(D)-J joining. Cell 59: 859-870.

39. Lewis SM. (1994) P nucleotide insertions and the resolution of hairpin DNA structures in mammalian cells. Proc. Natl. Acad. Sci. U.S.A. 91: 13321336.

40. Frippiat JP, Williams SC, Tomlinson IM, et al. (1995) Organization of the human immunoglobulin lambda light-chain locus on chromosome 22q11.2. Hum. Mol. Genet. 4: 983-991.

41. Frippiat JP, Dard P, Marsh S, Winter G, Lefranc MP. (1997) Immunoglobulin lambda light chain orphons on human chromosome 8q11.2. Eur. J. Immunol. 27: 1260-1265.

42. Daley MD, Olee T, Peng HQ, Soto-Gil RW, Chen PP, Siminovitch KA. (1992) Molecular characterization of the human immunoglobulin $\mathrm{V}$ lambda I germline gene repertoire. Mol. Immunol. 29: 10311042.

43. Williams SC, Winter G. (1993) Cloning and sequencing of human immunoglobulin $\mathrm{V}$ lambda gene segments. Eur. J. Immunol. 23: 1456-1461.

44. Ch'ang LY, Schnell MG, Ringelberg CS, Weiss D, Solomon A. (1995) Molecular characterization of a human V $\lambda$ VIII germline gene. Mol. Immunol. 32: 49-55.

45. Deftos $M$, Soto-Gil R, Quan $M$, Olee $T$, Chen PP. (1994) Utilization of a potentially universal downstream primer in the rapid identification and characterization of $\mathrm{V}$ lambda genes from two new human V lambda gene families. Scand. J. Immunol. 39: 95-103.

46. Ch'ang LY, Yen CP, Besl L, Schell M, Solomon A. (1994) Identification and characterization of a functional human Ig VAVI germline gene. Mol. Immunol. 31: 531-536.

47. Ignatovich O, Tomlinson IM, Jones PT, Winter G. (1997) The creation of diversity in the human immunoglobulin $\mathrm{V} \lambda$ repertoire. J. Mol. Biol. 268: 69-77.

48. Blomberg BB, Solomon A. (1997) The murine and human lambda light chain immunoglobulin loci: organization and expression. In: Herzenberg LA, Weir DM, Herzenberg LA, Blackwell C (eds). Handbook of Experimental Immunology. Blackwell Science, Inc., Boston. Fifth Edition.

49. Bauer TR Jr, Blomberg B. (1991) The human lambda L chain Ig locus. Recharacterization of JC lambda 6 and identification of a functional JC lambda 7. J. Immunol. 146: 2813-2820.

50. Vasicek TJ, Leder P. (1990) Structure and expression of the human immunoglobulin lambda genes. J. Exp. Med. 172: 609-620.

51. Niewold TA, Murphy CL, Weiss DT, Solomon A. (1996) Characterization of a light chain product of the human JC lambda 7 gene complex. J. Immunol. 157: 4474-4477.

52. Dariavach P, Lefranc G, Lefranc MP. (1987) Human immunoglobulin $C$ lambda 6 gene encodes the Kern $+O z-$ lambda chain and $\mathrm{C}$ lambda 4 and C lambda 5 are pseudogenes. Proc. Natl. Acad. Sci. U.S.A. 84: 9074-9078.

53. Udey JA, Blomberg B. (1987) Human lambda light chain locus: organization and DNA sequences of three genomic $\mathrm{J}$ regions. Immunogenetics 25: 63-70.

54. Ishikawa $H$, Ziff $M$. (1976) Electron microscopic observations of immunoreactive cells in the rheumatoid synovial membrane. Arthritis Rheum. 19: $1-14$.

55. Brown KA, Perry ME, Mustafa Y, et al. (1995) The distribution and abnormal morphology of plasma cells in rheumatoid synovium. Scand. J. Immunol. 41: $509-517$.

56. Kelley DE, Perry RP. (1986) Transcriptional and posttranscriptional control of immunoglobulin mRNA production during B lymphocyte development. Nucl. Acids Res. 14: 5431-5447.

57. Klein U, Küppers R, Rajewsky K. (1997) Evidence for a large compartment of IgM-expressing memory B cells in humans. Blood 89: 1288-1298.

58. Clausen BE, Bridges SL Jr, Lavelle JC, et al. (1998) Clonally related immunoglobulin $\mathrm{V}_{\mathrm{H}}$ domains and nonrandom use of $\mathrm{D}_{\mathrm{H}}$ gene segments in rheumatoid arthritis synovium. Mol. Med. 4: 240-257.

59. Campbell MJ, Zelenetz AD, Levy S, Levy R. (1992) Use of family specific leader region primers for PCR amplification of the human heavy chain variable region gene repertoire. Mol. Immunol. 29: 193-203.

60. Pääbo S, Higuchi RG, Wilson AC. (1989) Ancient DNA and the polymerase chain reaction. J. Biol. Chem. 264: 9709-9712.

61. Pääbo S, Irwin DM, Wilson AC. (1990) DNA damage promotes jumping between templates during enzymatic amplification. J. Biol. Chem. 265: 47184721.

62. Lundberg KS, Shoemaker DD, Adams MW, Short JM, Sorge JA, Mathur EJ. (1991) High-fidelity amplification using a thermostable DNA polyermase isolated from Pyrococcus furiosus. Gene 108: $1-6$. 
63. Tindall KR, Kunkel TA. (1988) Fidelity of DNA synthesis by the Thermus aquaticus DNA polymorphism. Biochemistry 27: 6008-6013.

64. Barnes WM. (1992) The fidelity of Taq polymerase catalyzing PCR is improved by an N-terminal deletion. Gene 112: 29-35.

65. Billips LG, Lassoued K, Nunez C, et al. (1995) Human B-cell development. Ann. N.Y. Acad. Sci. 764: $1-8$.

66. Kubagawa H, Cooper MD, Carroll AJ, Burrows PD. (1989) Light-chain gene expression before heavy-chain gene rearrangement in pre-B cells transformed by Epstein-Barr virus. Proc. Natl. Acad. Sci. U.S.A. 86: 2356-2360.

67. Schroeder J, H. W, Burrows PD, Cooper MD, Kubagawa $H$. (1992) $\mathrm{N}$ region addition and unusual CDR3 length distributions in $\kappa$-chain only pre-B cells [abstract]. J. Cell. Biochem. S17B: 235.

68. Nishimoto N, Kubagawa H, Cooper MD. (1991) Comparison of pre-B cell differentiation in normal and X-linked agammaglobulinemia (XLA) individuals [abstract]. FASEB J. 5: 1346.

69. Goossens T, Klein U, Küppers R. (1998) Frequent occurrence of deletions and duplications during somatic hypermutation: implications for oncogene translocations and heavy chain disease. Proc. Natl. Acad. Sci. U.S.A. 95: 2463-2468.

70. Wilson PC, de Bouteiller O, Liu YJ, et al. (1998) Somatic hypermutation introduces insertions and deletions into immunoglobulin $\mathrm{V}$ genes. J. Exp. Med. 187: 59-70.

71. Bridges SL Jr, Lee SK, Koopman WJ, Schroeder HW Jr. (1993) Analysis of immunoglobulin gamma heavy chain expression in synovial tissue of a patient with rheumatoid arthritis. Arthritis Rheum. 36: 631-641.

72. Ruff-Jamison S, Glenney J. (1993) Requirement for both $\mathrm{H}$ and $\mathrm{L}$ chain $\mathrm{V}$ regions, $\mathrm{VH}$ and $\mathrm{VK}$ joining amino acids, and the unique $\mathrm{H}$ chain $\mathrm{D}$ region for the high affinity binding of an antiphosphotyrosine antibody. J. Immunol. 150: 3389-3396.

73. Randen I, Brown D, Thompson KM, et al. (1992) Clonally related IgM rheumatoid factors undergo affinity maturation in the rheumatoid synovial tissue. J. Immunol. 148: 3296-3301.

74. Randen I, Thompson KM, Pascual V, et al. (1992) Rheumatoid factor $V$ genes from patients with rheumatoid arthritis are diverse and show evidence of an antigen-driven response. Immunol. Rev. 128: 49-71.

75. Martin T, Crouzier R, Blaison G, Levallois H, Pasquali JL. (1993) A minor group of rheumatoid factors isolated from a patient with rheumatoid arthritis is derived from somatically mutated Vkl genes further evidence that rheumatoid factors during autoimmune diseases undergo an antigen driven maturation. Autoimmunity 15: 163-170.
76. Olee T, Lu EW, Huang DF, et al. (1992) Genetic analysis of self-associating immunoglobulin G rheumatoid factors from two rheumatoid synovia implicates an antigen-driven response. J. Exp. Med. 175: 831-842.

77. Schroder ARE, Greiner A, Seyfert C, Berek C. (1996) Differentiation of B cells in the nonlymphoid tissue of the synovial membrane of patients with rheumatoid arthritis. Proc. Natl. Acad. Sci. U.S.A. 93: 221-225.

78. Bridges SL Jr, Clausen BE, Lavelle JC, Fowler PG, Koopman WJ, Schroeder HW Jr. (1995) Analysis of immunoglobulin gamma heavy chains from rheumatoid arthritis synovium: evidence of antigen-driven selection. Ann. N.Y. Acad. Sci. 764: 450-452.

79. McBlane JF, van Gent DC, Ramsden DA, et al. (1995) Cleavage at a V(D)J recombination signal requires only RAG1 and RAG2 proteins and occurs in two steps. Cell 83: 387-395.

80. Gellert M. (1997) Recent advances in understanding $\mathrm{V}(\mathrm{D}) \mathrm{J}$ recombination. Adv. Immunol. 64: 3964.

81. Prak EL, Weigert M. (1995) Light chain replacement: a new model for antibody gene rearrangement. J. Exp. Med. 182: 541-548.

82. Chen C, Prak EL, Weigert M. (1997) Editing disease-associated autoantibodies. Immunity 6: 97105.

83. Pelanda R, Schwers S, Sonoda E, Torres RM, Nemazee D, Rajewsky K. (1997) Receptor editing in a transgenic mouse model: site, efficiency, and role in B cell tolerance and antibody diversification. Immunity 7: 765-775.

84. Han S, Dillon SR, Zheng B, Shimoda M, Schlissel MS, Kelsoe G. (1997) V(D)J recombinase activity in a subset of germinal center B lymphocytes. Science 278: 301-305.

85. Papavasiliou F, Casellas R, Suh H, et al. (1997) $V(D) J$ recombination in mature $B$ cells: a mechanism for altering antibody responses. Science 278: 298-301.

86. Han S, Zheng B, Schatz DG, Spanopoulou E, Kelsoe G. (1996) Neoteny in lymphocytes: Ragl and Rag2 expression in germinal center B cells. Science 274: 2094-2097.

87. Ziff M. (1974) Relation of cellular infiltration of rheumatoid synovial membrane to its immune response. Arthritis Rheum. 17: 313-319.

88. Iguchi T, Ziff $M$. (1986) Electron microscopic study of rheumatoid synovial vasculature. Intimate relationship between tall endothelium and lymphoid aggregation. J. Clin. Invest. 77: 355361.

89. van Dinther-Janssen AC, Pals ST, Scheper R, Breedveld F, Meijer CJ. (1990) Dendritic cells and high endothelial venules in the rheumatoid synovial membrane. J. Rheumatol. 17: 11-17.

90. Randen I, Mellbye OJ, Førre O, Natvig JB. (1995) 
The identification of germinal centres and follicular dendritic networks in rheumatoid synovial tissue. Scand. J. Immunol. 41: 481-486.

91. Steere AC, Duray PH, Butcher EC. (1988) Spirochetal antigens and lymphoid cell surface markers in Lyme synovitis. Comparison with rheumatoid synovium and tonsillar lymphoid tissue. Arthritis Rheum. 31: 487-495.

92. Schröder ARE, Sieper J, Berek C. (1997) Antigendependent B cell differentiation in the synovial tissue of a patient with reactive arthritis. Mol. Med. 3: 260-272.

93. Kumon I. (1992) In situ characterization of mono- nuclear cell phenotype in intrahepatic lymphoid follicles in patients with chronic viral hepatitis. Gastroenterol. Jpn. 27: 638-645.

94. Freni MA, Artuso D, Gerken G, et al. (1995) Focal lymphocytic aggregates in chronic hepatitis C: occurrence, immunohistochemical characterization, and relation to markers of autoimmunity. Hepatology 22: 389-394.

95. Mosnier JF, Degott C, Marcellin P, Henin D, Erlinger S, Benhamou JP. (1993) The intraportal lymphoid nodule and its environment in chronic active hepatitis C: an immunohistochemical study. Hepatology 17: 366-371. 